\title{
Bridging the physical and virtual with mobile media
}

Steven Lam

Master Thesis by Composition

Victoria University of Wellington

2016 



\section{Bridging the physical and virtual with mobile media}

Steven Lam

A thesis by composition submitted to Victoria University of Wellington in fulfilment of the requirements for the degree of Master of Design Innovation in Computer Graphics.

Victoria University of Wellington

2016

A video file accompanies this thesis and can be found at:

< https://vimeo.com/108457935 >

The code repository for the developed compositions can be found at:

< https://github.com/Asteral/stevenlam-masters > 



\section{Abstract}

This thesis examines how mobile technologies can contribute towards bridging physical and virtual space through interactive, and location-specific, media experiences. Building on a research analysis of contextual discussions and precedents, it is noticeable that there is a discord between physical and virtual space usage as they are often utilised in different situational settings. This thesis therefore develops a mobile application as a wider investigation into how the physical setting and live data can be used to achieve a better link for contextualised content between the physical and virtual in urban areas. It explores this by making a location specific media experience, where the limits of the physical space are incorporated as boundaries in the virtual environment. Further to this, live data is used to influence the dynamics of the environment so that conditions are reflective of the physical world. These investigations are utilised with Augmented Reality, providing an end application that allows the viewer to physically explore urban space within an interactive mobile media experience. This approach offers a new perspective in urban space exploration and mobile media design, highlighting that contextual significance in media experiences are important aspects to consider and design for. Ultimately, such approaches may lead to larger narratives and experiences encompassing entire cities, or other diverse geographies. 


\section{Acknowledgements}

I would like to thank my supervisor Doug Easterly for the patience, support and knowledge that allowed me to pursue this thesis. A lot of the discussions we had helped me with great ideas in developing the theoretical stance and the designs presented here.

I would also like to thank Xiaodan Gao of Victoria learning support for the assistance in guiding my writing and keeping me on track. Without the help I would have surely been lost.

My thanks also to Bernard Guy, the lecturers of the Media and Industrial Design programmes, faculty staff and my fellow classmates. Their presence and support made the studies a little less pressured and more fun in the studio.

Lastly, my thanks to my family who have supported me with great patience as I undertook this endeavour. 


\section{Table of Contents}

Abstract I

Acknowledgements

Table of Contents $\quad$ V

$\begin{array}{ll}\text { Chapter 1. Introduction } & 01\end{array}$

Motivation 03

Overview 04

$\begin{array}{ll}\text { Methodology } & 06\end{array}$

$\begin{array}{ll}\text { Chapter 2. Literature Review } & 09\end{array}$

Augmented Urban Spaces $\quad 12$

Ubiquitous Computing $\quad 15$

Augmented Reality $\quad 19$

Summary 23

Chapter 3. Analysis and Criteria $\quad 25$

$\begin{array}{ll}\text { Research Analysis } & 27\end{array}$

Precedent Works $\quad 29$

Precedent Analysis $\quad 35$

Design Criteria $\quad 36$

Chapter 4. Design Process 39

Defining the Location $\quad 42$

Linking Physical and Virtual $\quad 46$

Live Data Integration $\quad 46$

Technical Details $\quad 47$

Design - Initial: Extinct NZ Birds $\quad 49$

Design - Revised: Echoes $\quad 59$

$\begin{array}{ll}\text { Chapter 5. Conclusions } & 73\end{array}$

Summary $\quad 75$

$\begin{array}{ll}\text { Discussion } & 77\end{array}$

$\begin{array}{ll}\text { Implications } & 79\end{array}$

$\begin{array}{ll}\text { Future Directions } & 80\end{array}$

$\begin{array}{ll}\text { Bibliography } & 83\end{array}$ 
Chapter 1 - Introduction 


\section{Introduction}

\section{Motivation}

This thesis examines how mobile media applications can bridge physical and virtual spaces in urban environments. Mobile media is widely used throughout daily life, however, the content of most media applications do not consider the user's physical surroundings as an important element to design for. This lack of consideration contributes to a discord in the usage of the spaces as individuals are not engaged to focus on more than one space at a time. There are some exceptions, for example: Ingress, a multiplayer location based game with conquest style gameplay; and Layar, an augmented reality browser that overlays information onto a user's immediate surroundings. However, the implementations of these applications are rather rudimentary and could incorporate more immersive approaches to enhance the user experience. The virtual content in these applications are generally just 'placed' into digital space that parallels the user's physical location; design considerations of spatial layout and environmental influences are left largely unexplored. Because of this lack of connection to the environment, it can still 'feel' like the virtual content is distinctly separate from the physical world, even though a greater presence is often intended.

By addressing this separation, enhanced contextual detail can be established for mobile media between physical and virtual spaces in urban areas. The urban city has generally been identified through physical geometric definitions, however, the advances in mobile technologies and ubiquitous computing in recent decades have heralded a stance from scholars such as Manovich (2006) and Aurigi \& De Cindio (2008) that the urban city is not just physical space but also digital as well. This Augmented Space as termed by Manovich (2006), promotes the idea that the physical is linked to the virtual and interactions are possible between them. This sets the table for designers and developers to explore media experience avenues that span across physical and virtual dimensions. By doing this, virtual content can be synchronised to 
physical world elements, bringing contextual significance to the urban city as a setting for virtual media experiences.

\section{Overview}

This thesis, alongside a compositional component, aims to promote the consideration of the physical and virtual in urban space as a potential focus area in mobile media development. The research is focused around the design of a location specific, Augmented Reality (AR) experience, where the content is designed with consideration to the boundaries of a chosen urban environment. These boundaries are defined by the buildings and other physical features that inhabit the space. This approach allows the viewer to immerse themselves in the physical environment and in the virtual world of the media experience when they interact with it through their mobile device. What this enables is a linked relationship between the physical space and virtual content, allowing for a greater context to be established as well as sense of presence in the media for the viewer.

The explorative designs in this research are focused towards the entertainment industry, outlining possible usage scenarios in urban space as well as exploring key features that are needed for the success of greater contextualised content. A mobile web application was first explored with a scenario that focused on illustrating extinct New Zealand birds in an AR setting. This application lead to a more focused exploration of an AR environment in a stand alone application built on the Unity game engine. The designs and ideas of these applications are presented as a foundation for future developers to consider more innovative developments of mobile media in urban settings. 
The research carried out initially reviews relevant literature and precedents to formulate a design basis. New media researcher Lev Manovich is discussed to present his formulation of Augmented Space, which has been adopted by scholars such as Alessandro Aurigi as an investigative approach in analysing how digital technologies affect urban space perceptions and usage. Further to this, Mark Weiser's vision of ubiquitous computing is drawn on to identify how ubiquitous computing research has lead technological advances to the current wave of computing in relation to our usage of mobile devices. Finally, an overview of Augmented Reality (AR) is presented with discussions from Ronald Azuma outlining the key challenges and issues faced, and how the developments of technologies have advanced this research area in recent years.

After the literature review, an analysis of precedent works is compared against the suggested approaches by researchers to formulate a design criteria. This design criteria is then applied to idea and concept construction, which is detailed to explore the current capabilities of technologies as well as the creative design approaches possible. Following this, an evaluation of the exploration is discussed and revisions are drawn and applied to a revised application design called Echoes. Echoes is then presented to showcase the implementations possible where finally, conclusions are drawn to discuss the findings and where this research might lead to in the future. 


\section{Methodology}

This thesis is formulated through a combination of qualitative literature analysis and a process of research through design. The analysis is applied to literature relevant to the thesis topic and seeks to present the key ideas that illustrate the focus area in this research. Research through design, starting with ideas and discussions afforded by current technologies, is then applied to construct conceptual designs envisioned as a result of the literature analysis and precedent works. This approach is taken so that the design process and output can be used to draw findings and conclusions to complete the thesis. The methodological approach of this thesis can be divided into two main phases.

Phase one is a qualitative analysis into the fields of Augmented Space, Ubiquitous Computing and Augmented Reality. It first seeks a foundation by identifying the key ideas and challenges that researchers such as Lev Manovich, Alessandro Aurigi and Mark Weiser have investigated in defining Augmented Space and Ubiquitous Computing. Next, Augmented Reality discussions from researchers and groups such as Ronald Azuma and HIT Lab NZ are detailed to gain insight into current AR application designs.

Phase two involves the design of concepts that apply the knowledge gained in Stage one. It adapts the Research Through Design discussions by Christopher Frayling which identifies design output as an approach for communicating results. (Frayling, 1993, p. 5). This process involves gathering precedents such as Ingress and Layar to construct a design criteria that will be applied to an initial design. The initial design will then be detailed and evaluated to contribute towards a revised design piece. A final discussion will then detail the approach findings where conclusions will be drawn to finalise the thesis. 
Chapter 2 - Literature Review 


\section{Literature Review}

The following literature review encompasses three topic areas: Augmented Space, Ubiquitous computing and Augmented Reality. This review starts off by providing a theoretical overview into Augmented Space defined by Lev Manovich in his paper The Poetics of Augmented Space. From this, further discussions into this field by Alessandro Aurigi and Fiorella De Cindio as well as contributors in their book Augmented Urban Spaces, are presented and drawn into the context of the urban city, detailing how the presence of enriched media environments through ubiquitous, pervasive and mobile technologies modify city living and urban space definition. After this, Ubiquitous computing is presented through discussions by Mark Weiser in his early visions within this field to provide insight into how the digital augmentation of space is realised. This is followed by current research into Context-Aware application design and Augmented Reality to draw parallels against the suggested views highlighted by the Augmented Space researchers.

These three topics are not entirely separated by their respective research areas, rather the developments are parallel, and at times, are cross disciplinary where each field affects the next through developing innovations. This combination of context from these three areas defines the rationale for this research in exploring the physical and virtual divide for mobile media in urban spaces. 


\section{Augmented Urban Spaces}

In his paper The Poetics of Augmented Space, Manovich (2006) presents Augmented Space as an approach to representing the relationship between physical and virtual elements in urban spaces. This term is derived from Augmented Reality, a technological approach for overlaying virtual information onto physical space, and is formulated by Manovich through three aspects he identifies in urban space: Surveillance, Cellspace and Digital Displays (Manovich, 2006, pp. 223-224). These three aspects for Manovich, transforms the concept of physical space into a data enriched space, allowing for information to be extracted from it, or delivered into it. Manovich highlights that this new concept of space is explored in a number of related research fields: Ubiquitous Computing, Augmented Reality, Tangible Interfaces, Wearable Computing, Intelligent Spaces and Context Aware Computing, to list a few, and states that the end result of the intended research is always the same: "overlaying the physical space with dynamic data". (Manovich, 2006, p. 223). Manovich terms this type of space as Augmented Space and he characterises it as being monitored and data dense; every point in 3D physical space has potential information which can be extracted.

To provide an example of this, the major city centers such as Tokyo, Seoul, London, New York and others can be seen as Augmented Spaces (Manovich, 2006, p. 231). The presence of electronic displays, mobile devices and video surveillance in the cities today effectively overlays information onto the urban environment (Allen, 2008, p. 29). What this does to the urban city is that it transforms the physical infrastructure to contain many different information flows. These information flows range from GPS position data to the wireless networks that enable conversations between people, and they are traversed by the city residents in a seamless manner with digital technologies and applications (Foth \& Sanders, 2008, p. 73). 
The notion of Augmented Space defined by Manovich has become a popular foundation for researchers that analyse the relationship between the physical and virtual in urban city space. For Aurigi and De Cindio (2008), their research discusses how media environments, ubiquitous computing and communication technologies modify city living and change the perspective of urban space. They argue against a distinct separation between the physical and virtual, stating that the different dimensions within an augmented city have now come to define each other, and concepts such as public vs private spaces, presence, and public discourse are all affected and shaped by the augmented urban space that we inhabit today (Aurigi \& De Cindio, 2008, p. 1).

This stance of a blurred boundary between the physical and virtual is further reflected in views presented by Katherine Willis who analysed how urban space usage is affected by the presence of digital technologies. Willis (2008) draws upon a Euclidean and topological understanding of space through a spatial framework which is summarised into the concepts of separation, boundedness, presence, linkage and temporality. This framework is used by Willis to identify that the urban city is commonly viewed as a metric space that is alongside a social setting defined from the interactions that take place within. However, Willis also argues that the ubiquitous presence of communication networks in urban areas have modified these traditional definitions on how space is viewed. The wireless and digital technologies have enabled social interactions in urban settings to transcend the physical limits and boundaries of the space, allowing for multiple social situations to take place at the same time.

To analyse this further, Willis conducted a case study into the spatial presence of wireless technologies in South-East London. Her results found that wireless technologies are not often seen by individuals through spatial definitions as there is 
no visual substance to identify with. Additionally, she also found that individuals spent more time in public spaces when they accessed the technologies that were present there, and that during this, the individual engagement with the physical space was passive as the user's attention was diverted towards the flows of information offered by the wireless technologies. This creates in Willis's views, a discord between the physical and social possibilities offered by wireless technologies as the two domains are operating on different situations and not working together as a unified domain. Willis suggests that that in order to resolve this disparity, it will be necessary to rethink the ways we act and define our physical world.

Heesang Lee also presented a similar point and draws on research in mobile media literature to examine the relationship between mobile networks and urban spaces. He specifically examined the psychological space of individuals with a survey of mobile landscapes directed at Korean university students in their twenties. He found that mobile technologies enabled user's to exist in multiple places at once as the existing euclidean framing space is transformed into "fluid, multiple and complex time-spaces where spatial and temporal boundaries are reordered and rearranged" (Lee, 2008, p. 43). He also found that the technologies produced social networks that created emotional qualities for urban areas in the everyday lives of their users. Lee notes that these emotional spaces shaped the user's perception of urban space as it contained a paradoxical quality that caused an ambivalent desire of wanting to be connected to others at all times while also wanting to be free from surveillance. This shaping of urban space leads Lee to argue that the contemporary urban city should be seen as a cyborg space, in the sense that human and machine bodies are mixed and that physical and virtual space is combined together. 


\section{Ubiquitous Computing}

While researchers have analysed the changing urban landscape in exploring Augmented Space, the developments of technologies that have enabled this have often been researched with a focus on the ubiquitous computing (ubicomp) visions presented originally by Mark Weiser. The current state of technology can be argued to have entered the third wave of computing, described by Weiser and Brown (1997) as the calm state, where technologies recede into the background norms of everyday life. These developments can be attributed largely to the widespread usage of mobile devices which have become more compact and more capable in functionality. This increased functionality has brought with it the information flows previously mentioned which has contributed towards blurring the boundaries between the physical and virtual realms. This blurred boundary has resulted in the disparity identified by the researchers in the section above. However, this disparity can be seen as an ongoing focus element in Ubicomp research as it has been a main focus area before the articulation of Augmented Space by Manovich. Research in this area has been referred to as Context-Aware computing, Ambient-Intelligence, LocationAwareness and sentient spaces.

Some early developments that sought to integrate physical and virtual elements together were carried out by Abowd, Dey, Orr, \& Brotherton (1998), who presented their developments in Context-Aware computing to promote a shift away from traditional desktop application design. They observed that many applications provided on portable devices were often duplicates of what already existed on desktops, and that few, if any, considered the mobility of the user as an important design aspect. They suggested that in order to break away from this, computing services needed to become Context-Aware and as mobile as their users. 
To explore their views, Abowd et al. (1998) presented four case studies of Context-Aware applications: CyberGuide, a digital tour guide that tracked the physical location of a user to provide location specific information; CyberDesk, a software application that aided users in using other software by providing suggestions and auto completion features; Savoir, a voice activated application that attempted to interpret user voice commands based on location to give relevant information; and Classroom 2000, an application that recorded lecture notes and interactions between teachers and students to detect emotional states to aid instructors and teachers. These case studies were presented within the domains of tourism, education and personal management, and each argued a strong case for Context-Aware computing in everyday life by identifying issues and offering solutions.

A similar study was performed by Björk, Holopainen, Ljungstrand, and Åkesson (2002) who examined how ubicomp technologies could be applied in context to games and entertainment. They identified that most computer games made little use of the physical environment beyond basic position data. Their wish to explore the physical world as a meaningful game element lead them to carry out a workshop where a series of proof-of-concept designs were created. These designs were aimed at exploring the potentials that new sensor technologies of the time offered. The research workshop resulted in three different game concepts and prototypes: Spygame, a world scale catch-the-ball game; Multi Monster Mania, an extension to an existing trading card game; and The Guild, envisioned not as a computer game per se but rather a social game that aimed at creating communities and spaces throughout urban city areas.

An observation that could be made in the developments for ubicomp contextual awareness in location based applications so far is that they have been largely focused on the individual user experience and how it can be enhanced by adapting physical 
elements into virtual landscapes. However, in another direction, enhancement can equally be established by community and social relationships driven by context based media interactions with physical environments. In the former Soviet Union and predominantly Russian speaking Diaspora, a gaming network called Encounter draws together a community of individuals who seek participation in location aware games. One popular form of location aware Encounter is aptly named Combat (Skhvatka) and is studied by Shklovski and Silva (2013) to analyse how technologies enable enhanced interactions in the experience of local urban environments with geographically diverse player communities. They identified Combat as a night time, urban exploration and team puzzle solving game similar to Orienteering and Treasure hunting. They noted that the puzzles in these games were often situated in abandoned urban areas that resulted from the collapse of the Soviet Union, and that the teams of players who competed against one another to solve the puzzles, were often split into two groups: a Field group that explored the urban spaces for puzzles and clues, and a remote HQ group that focused on communication and solving the puzzles. The Field players often lived in local proximity of the game play area while the remote HQ group were often players outside of the area. For many of these players, this setup was seen as a reclamation of abandoned urban spaces as new meanings and purpose were embedded into them (Shklovski and Silva, 2013, p. 351). This particular usage of space coupled together with connected game play in solving puzzles, created and fostered a subculture that utilised local engagement with physical environments for contextual game play and had encouragement and support from an online community (Shklovski and Silva, 2013, pp. 356-357).

Another focus area in ubicomp research that explored (implicitly) the disparity between the physical and virtual elements in urban areas are the concepts of Ambient Intelligence (AmI) and Sentient Spaces. While location and mobility has 
been one of the primary factors considered in research, the physical environment and the information flows offered by emerging technologies make possible the idea of a reactive environment with anticipatory intelligence to enhance or aid in individual experiences. In a study by Zaharakis and Komnious (2012) who examined Ubicomp developments from its inception, the concept of AmI is detailed as spaces that are sensitive to the activities and actions that take place there. They are spaces that react to individuals by assisting in the events that occur and as Crang and Graham (2007) suggests, AmI "is a world where we not only think of cities but cities think of us, where the environment reflexively monitors our behaviour" (p. 789).

These Ubicomp developments in Context-Aware, location aware, AmI and sentient spaces commonly draw on the information flows that are present in the surrounding environment. These information flows are sometimes enabled by sensor technologies which have now become a standard feature in mobile devices today. The applications that have been detailed by researchers above, draw on some of the capabilities offered by these sensors, and they illustrate features and implementations that contribute to the overall end user experience. By adapting these solutions into media applications, the identified disparity between physical and virtual spaces will be lessened, providing a better contextual link and enhancing the media experience as well. 


\section{Augmented Reality}

In parallel to the Ubicomp developments outlined above, Augmented Reality (AR) has also explored the melding of physical and virtual elements. Originally conceived by Caudell and Mizell (1992) as a productivity tool to aid in the production of aircraft, early AR production setups were often encumbering desktop workstations and displays where the visual augmentation of virtual content was rudimentary at best. In the last decade however, developments have been adapted onto the mobile platform and the mobility and increased capability of devices have provided an ideal environment for AR to be explored and deployed.

The identification of an Augmented Reality is commonly viewed through three key characteristics that were outlined by Ronald Azuma in his survey paper presented in 1997. The first is that it combines real and virtual; the second is that it is interactive in real time; and the third is that it is registered in 3-Dimensional space. The discussion of this definition also encompassed the identification of the key limitations in registration and sensing techniques (Azuma, 1997). An in-depth discussion of the registration issue illustrated the problem where if objects in the physical and virtual are not registered or aligned correctly, then the illusion of both worlds coexisting will be lost. Further to this, a phenomenon called "Visual Capture" termed by Welch (1978) (as cited in Azuma 1997) increased the difficulty in detecting registration errors; "visual capture" being the tendency of the brain to believe what the eyes see over the other senses. Apart from these technical challenges of the time (most of which been lessened in current technologies), Azuma (1997) provided a groundwork for further research, outlining various areas such as the perceptual and psychophysical fields, portability, multimodal displays for difference senses and social plus political fields. This survey in AR was later updated in 2001 where many of the issues were revised (Azuma et al., 2001). 
Augmented Reality in its fundamental definition, combines physical and virtual elements, as such that in relation to the disparity between the two realms identified previously, this area of research is, what one might say, appropriate to explore. In one early AR exploration, an application called AR Quake was developed. Thomas et al. (2002a) presented their developments in AR Quake which is an Augmented Reality game that relies on superimposing virtual objects onto the physical world. AR Quake was a project that centered on extending the first person shooter game - "Quake" - to the physical world. The gameplay involved the player moving about in the physical world where the virtual environment and characters of the game were mapped to the physical environment. This project was one of the first AR games that could be played outdoors and had a system that involved geo-location tracking and haptic feedback through the controller.

AR Quake identified AR as a possible entertainment application and explored the use of a freely available game engine as test case. The various techniques that were used such as projection mapping and image recognition were advances in computer graphics technology at the time and helped minimised the issues with the registration. However as noted in a usability test by Thomas, Close, Krul and Piekarski (2002b), the graphics were still "jumpy" which caused players to be distracted from the content and experience.

In another AR exploration, Dow, Mehta, Lausier, MacIntyre and Mateas, (2006) ported a desktop drama game called Facade to the AR platform. Their version of Facade was developed with an Artificial Intelligence system that reacted to player actions through a series of scripted scenarios. It was deployed in a room where the physical setup of objects such as chairs and tables were reflected into the virtual space of the game. The environment and game scenario was used to explore the behaviours 
and interactions players had between physical and virtual elements. This AR version of Facade attempted to create an unconstrained virtual gaming environment where players could interact and move freely about the reactive objects in the scene.

A more recent AR game was developed by Clark and Piumsomboon (2011) of HitLab NZ who created an AR Racing game with the Microsoft Kinect. The Kinect is a gaming peripheral with a stereo depth sensing camera capable of tracking positioning in 3 dimensional spaces. This tracking capability enabled a greater level of accuracy in the registration of the virtual to physical alignment and is discussed in detail by Clark and Piumsomboon (2011) to provide an overview into how a more realistic AR experience can be created. Their discussion identified that to improve the AR experience, it is necessary for virtual content to behave more realistically in the physical environment. To accomplish this, Clark and Piumsomboon (2011) adapted the physical environment that was captured by the Kinect and utilised it as the race track for the game. The virtual race car was also adapted with a physics system to allow for interactions with the physical environment. The result of this implementation enabled players to experience a more reactive environment with a physical contextual link when they played the game.

While most AR research and literature discussed so far has required some form of a desktop computer setup to function, the current generation mobile platforms are also capable of deploying AR applications. A location aware information tool called Leaf++, was developed by Iaconesi, Simeone, and Hendrickson (2011) and used AR techniques to provide information on plants and foliage. The intent of this application was to augmented an individual's vision with a cognitive overlay of information about the user's natural surrounding environment. Each time a user activated the application on their surroundings, a dynamic and real time update to a virtual map landscape 
was performed. This virtual landscape changed depending on the updated data and provided a feedback of sounds and visuals. While this application had originally intended to raise awareness on ecology and the natural environment by providing educative information, Iaconesi et al. (2011) extended the usage of this tool to more artistic forms, drawing in the physical environment as a driving factor for a media experience.

Another AR exploration on the mobile device was carried out by Aydın, Gensel, Calabretto and Tellez (2012) who presented ARCAMA-3D, an AR platform for 3D map visualisations on mobile devices. They highlighted that most location based media content was non interactive, and that AR was just commonly used to provide extra information about the surrounding physical world. They also highlighted that individual's often referred to their mobile devices for navigation when they travelled about unknown areas in a city, which meant that there was more of a focus on the mobile screen in front of them and less on the physical environment around them. To explore these identified issues, Aydin et al. (2012) developed ARCAMA-3D with the aim of keeping the focus of the individual on the physical environment. They explored this by drawing on the user's preferences gathered from social networks and the surrounding context to provide a personalised information overlay. This overlay was also interactive and allowed users to realign virtual content that may have initially been registered incorrectly to the physical world. This interactivity and display of personalised content that reflected the physical environment meant that user's did not have to interpret as much information in order to connect the virtual elements to their surrounding world. This enabled the context to be recognised more easily which minimised the distinctive gap between physical and virtual elements. 


\section{Summary}

The literature and research examined in this section has been centered on the blurring distinction between the physical and virtual world. With the articulation of Augmented Space, researchers have examined how urban spaces are used in the presence of mobile and wireless technologies. They identified that although these technologies offered parallel virtual spaces in urban areas, individual's often focused on one space at a time. This separation of focus caused what is identified as a disparity in the usage of the two spaces, and that in order to lessen this, researchers have suggested that a greater consideration between physical and virtual elements is needed in urban planning and mobile application design.

In Ubicomp research, this consideration between the differing spaces has long been an implicit focus area. The developments in Ubicomp have examined the ideas of Context-Awareness, Location-Awareness, and Ambient-Intelligence, providing many design directions that sought to enhance user experiences through establishing a link between physical and virtual elements. Additionally in parallel to this, Augmented Reality research has also explicitly explored the physical and virtual through combining the worlds together with graphical overlays. However, despite the advances made in these research areas, and mobile devices becoming more capable in delivering graphics and real time data gathering functions, the developments in mobile media have still largely been limited to rudimentary visual overlays and varying forms of digital maps. In order to advance this further to establish a greater contextual link between physical and virtual spaces, and in turn, lessen the disparity between them, the use of 3D graphics and real time information will need to be considered in mobile media applications. 
Chapter 3 - Analysis and Criteria 


\section{Analysis and Criteria}

The following section details the analysis of research discussed in the previous chapter to provide a foundation towards formulating a design criteria. The design criteria is constructed by comparing this foundation against precedent works to identify common elements and features that should be considered in the mobile media designs towards bridging physical and virtual space.

\section{Research Analysis}

The following is an analysis of the projects that were outlined in the previous chapter. These projects had elements that researchers commonly implemented and discussed in their research.

- Mobility - The most common element that could be identified is the consideration for user mobility. The term mobility refers to the location and orientation tracking approaches that researchers implemented into their applications. These applications often had content designed with the mobility factor as the main user interaction mechanic.

- Context/Data Awareness - Another common element suggested mainly in ubicomp developments is the idea of context awareness. Context awareness refers to the capability for applications to react dynamically with the surrounding environment. These reactive processes could be visual or non visual, providing changing virtual content that establishes that the application is linked to the immediate surroundings or activities of the user. 
- Visual Graphics - The visual designs were commonly 2D digital maps or 3D virtual overlays on top of a live camera feed. The 2D maps varied in terms of visual styles but they were mostly used to position virtual elements in relation to GPS positions. Similarly, the 3D AR overlays also displayed virtual elements in relation to GPS however most content was often tracked to the physical features of the surrounding environment as well.

Precedent applications were analysed next to gain insight into the current approaches that developers undertook in their application designs. This was to confirm whether the suggested approaches by researchers in academia were applied in commercial applications or not. The analysis was also conducted to formulate a design criteria for idea and concept generation. The formulation of this criteria was aimed at improving upon the current status quo of developer implementation views.

The precedent works that were examined were mobile applications focused in the entertainment industries. These precedents were chosen for the development features, user base, and popularity reviews reported on the Google Play and Apple's App store. Analysis of these applications were conducted primarily through a comparison of game play and normal operation. 


\section{Precedent Works}

\section{Ingress}
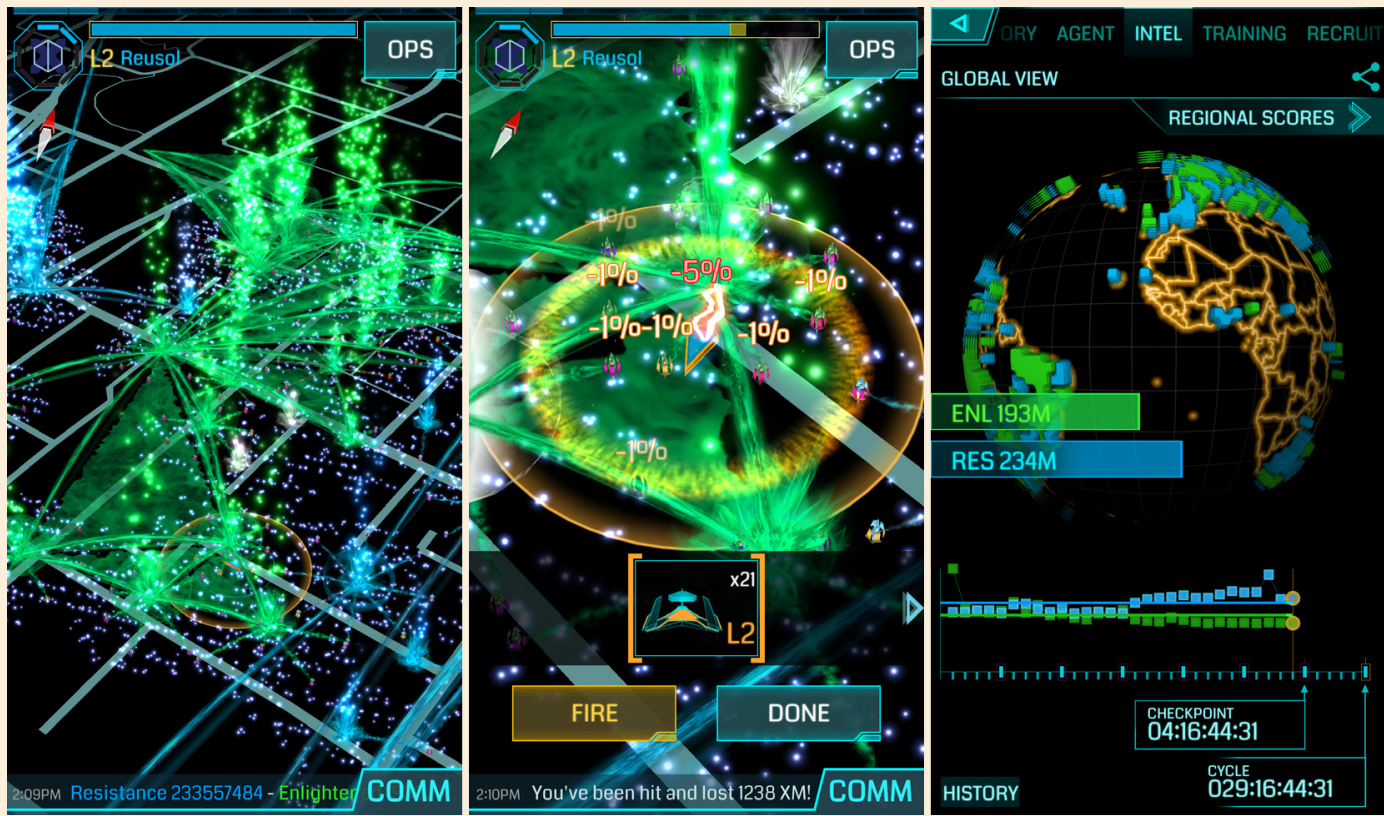

Figure 1.

Ingress

screen captures

(2014).

Developed by Google Niantic Labs, Ingress is a massively multiplayer online role playing game (MMORPG) that incorporates an AR map with GPS dependent gameplay. Through the use of a 2D digital map display augmented with rudimentary $3 \mathrm{~d}$ visual effects, urban landmarks and public places are established as "portals" and players work together and compete with one another in a classic, 'capture the flag' scenario to claim experience points as well as territory for their team. 


\section{Layar}

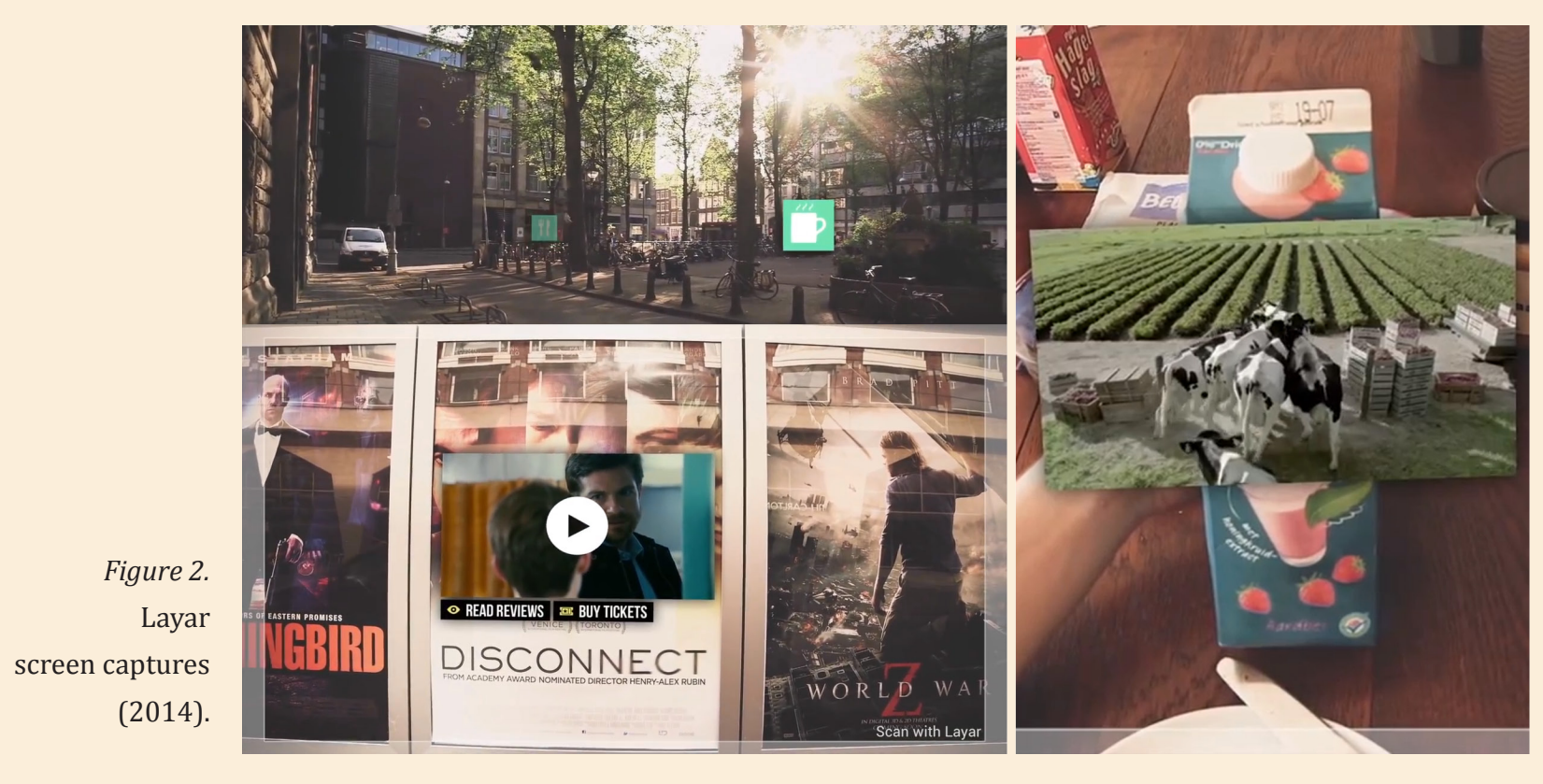

Created by a company based in Amsterdam, Layar is an Augmented Reality browser platform for overlaying virtual content onto the physical world. Developers create 'layers' of virtual content to share out to the world via the platform offered by this service. Content offered in this application range from AR books, AR advertisements and locative AR media. 


\section{Shadow Cities}
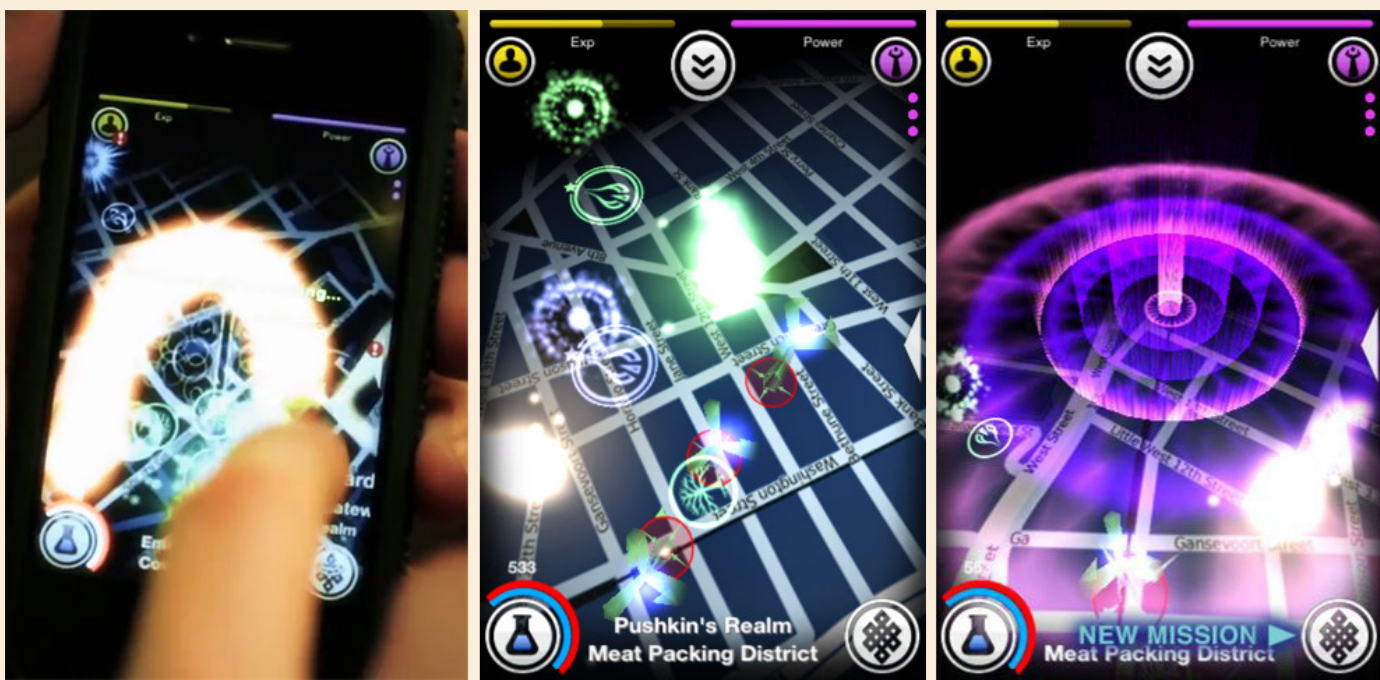

Figure 3.

Shadow Cities screen captures (2014).

Developed by Finland based company Grey Area, Shadow cities was an iPhone MMORPG with augmented reality and location based elements. This game tracked the player's position and allowed active battles to take place with creatures within proximity on a GPS enabled digital map. This map would also outline areas of interest where missions could also be completed for points and experience. 


\section{colAR Mix}

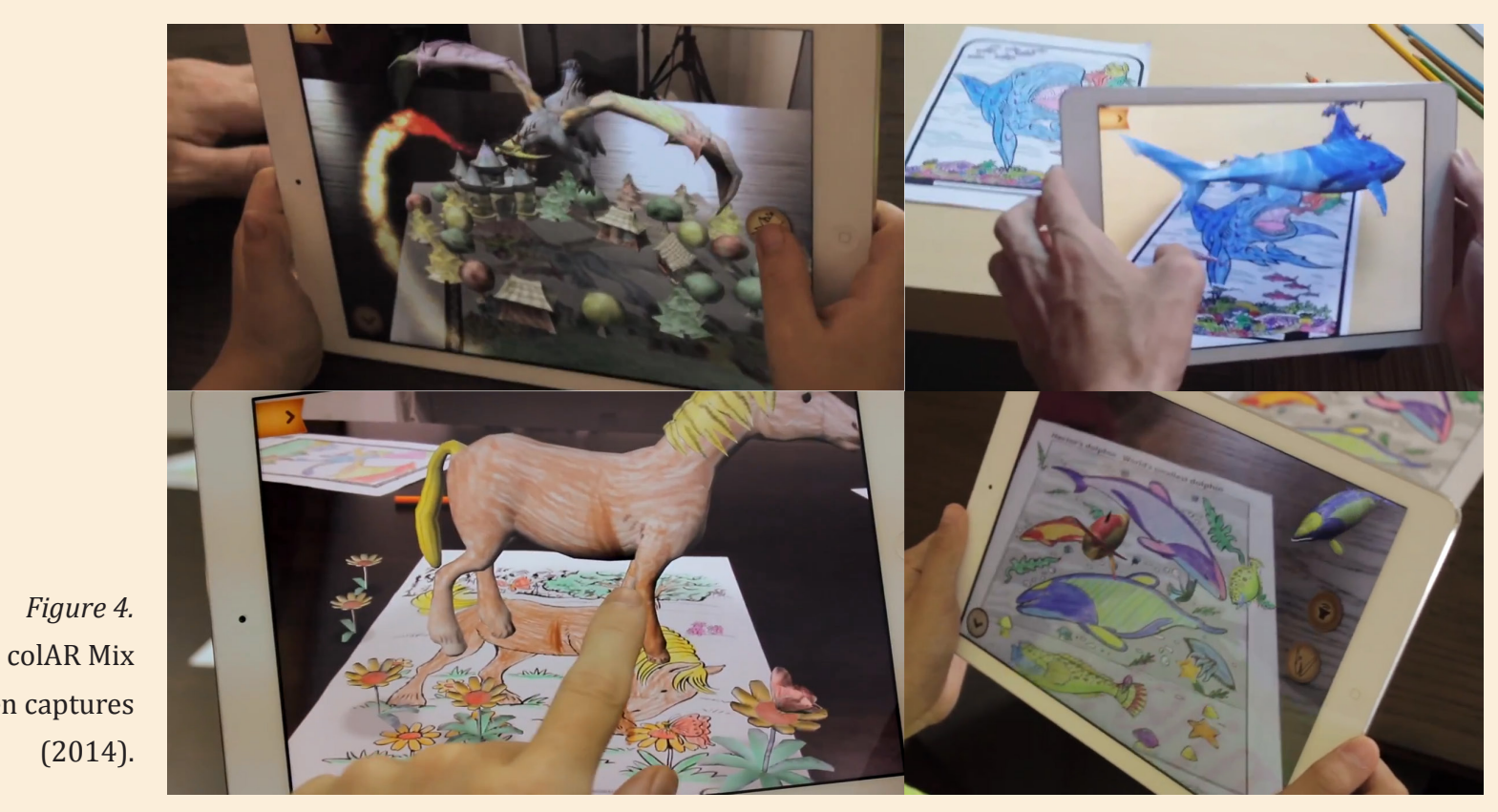

Clark, Dünser and Grasset (2011) of HitLab NZ developed an interactive augmented reality colouring book application which is currently being commercialised by Puteko Limited as colAR Mix. This application utilises colouring book pages as AR markers and brings the picture to life with animated virtual content. The animated virtual content is accompanied by a narration that explains the animals and characters that are displayed. 


\section{Droid Shooting}

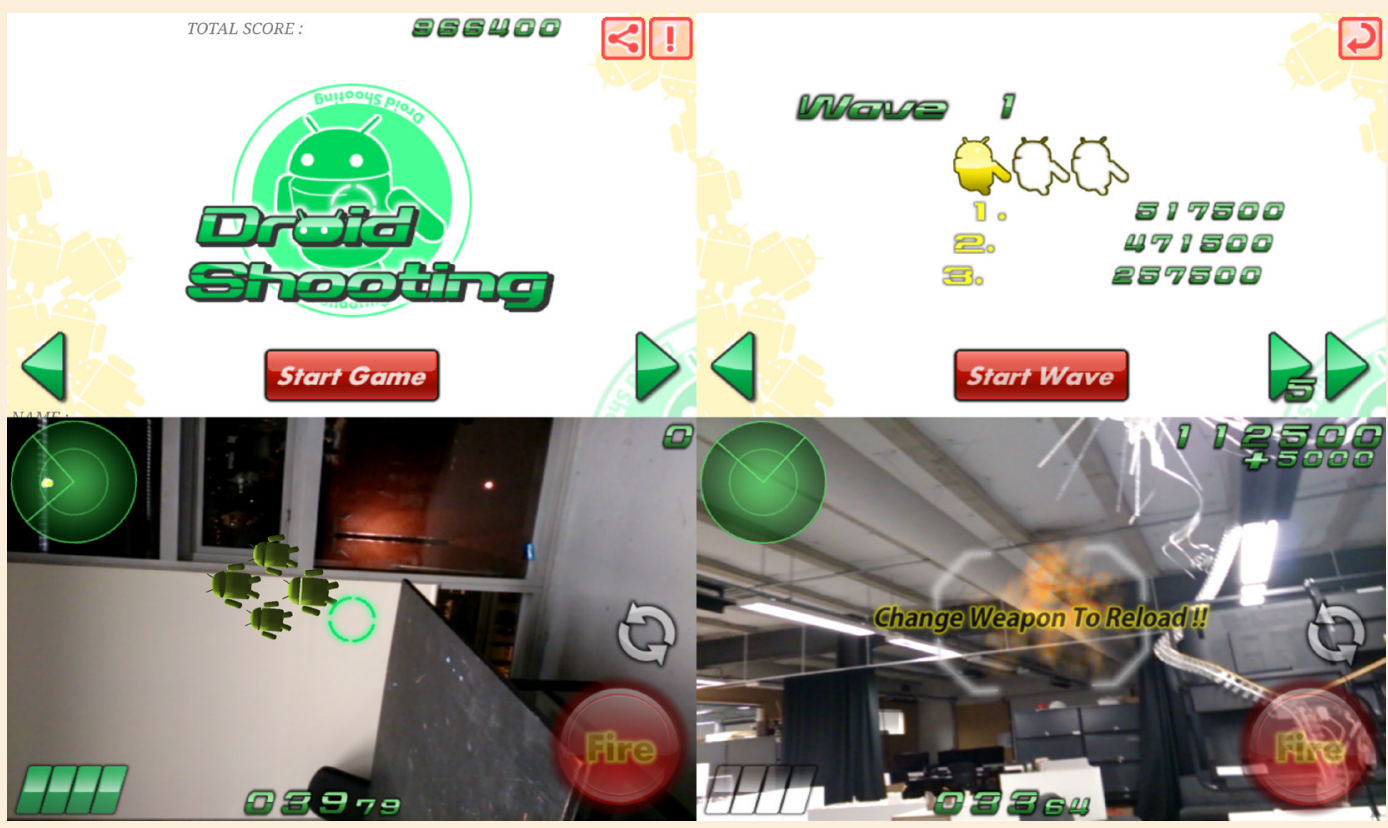

Figure 5.

Droid Shooting screen captures (2014).

Created by Quest Com, Droid Shooting is an arcade based, real time shooter game with AR elements. This game is tracked in $3 \mathrm{D}$ with the physical environment as a backdrop and is reminiscent of retro shooter games. The game has enemies swarming in from all directions and the player has to turn physically with their mobile device to look around and shoot. 


\section{Parallel Kingdom MMO}

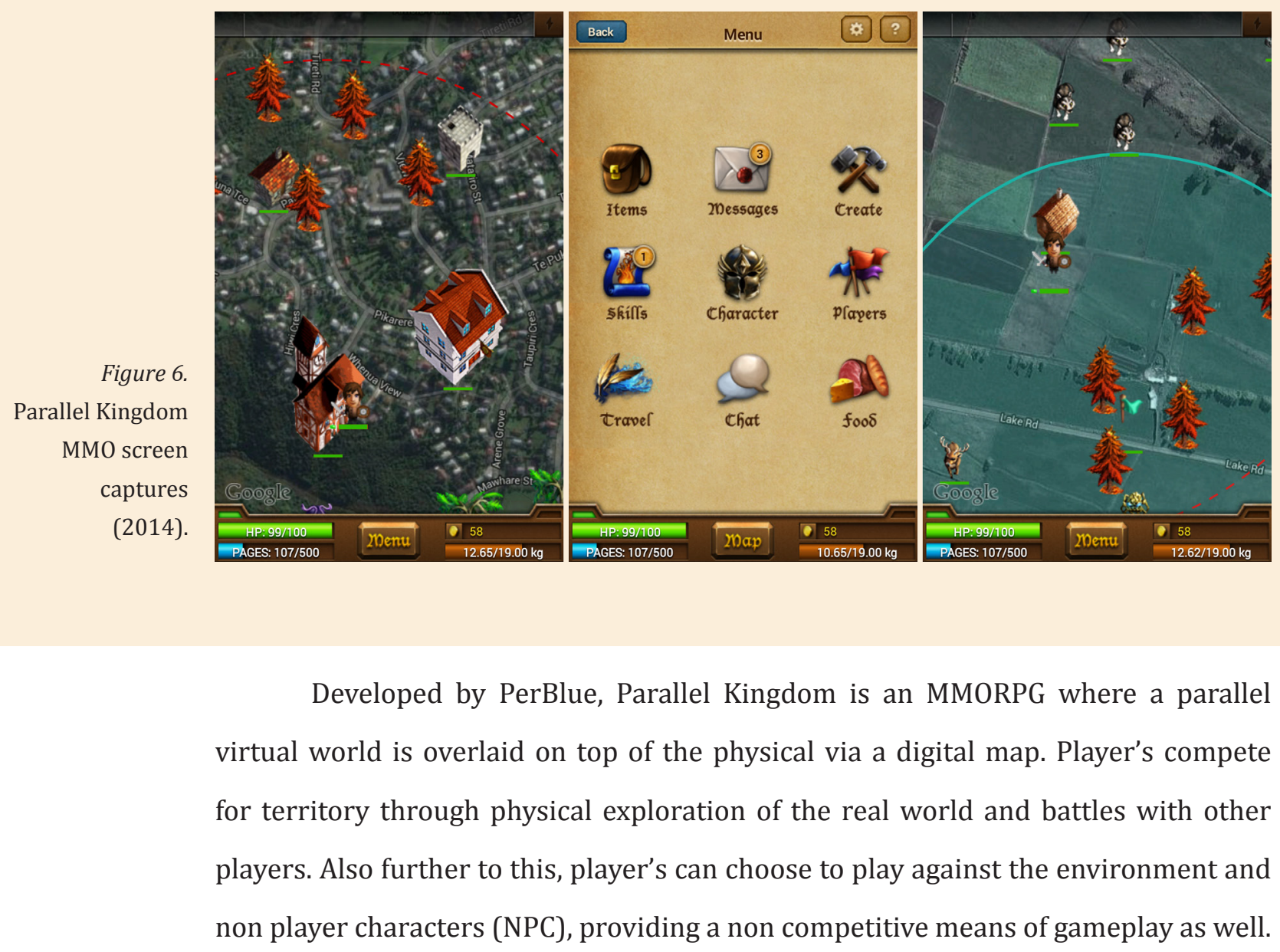




\section{Precedent Analysis}

The listed precedents above all contained a common utilisation of mobility similar to the suggested approaches by researchers in their application design. Ingress, Layar, Shadow Cities and Parallel Kingdoms tracked user location with GPS whereas Droid Shooting and ColAR Mix tracked user orientation with physical features and markers. These movement mechanics was one of the key features in using the applications as they were often leveraged for user interaction controls.

In regards to the context/data awareness of these applications, the virtual content of these applications seldom leveraged any data gathering services to track surrounding physical variances such weather and light conditions. The lack of any awareness meant that the virtual content often operated in a static and unchanging manner to the dynamics of the physical environment. This is in contrast to the suggested approaches by researchers where they argued that contextual data integration would establish a more enhanced media or user experience.

Finally, the observed graphical implementations of these precedents were similar to those detailed in the literature. The location aware AR applications (Ingress, Shadow Cities and Parallel Kingdoms) deployed a 2D digital map where points of interest were displayed with geotagged markers. The AR applications (Layar, Droid Shooting, ColAR Mix) utilised 3D tracking on a live camera feed to overlay virtual content onto the physical environment. Furthermore, as a side note, Ingress and ColAR Mix also presented animated virtual content in their visual implementations as well. 


\section{Design Criteria}

From the observations made above, the following design criteria was constructed to identify the key elements that have been commonly implemented across Ubicomp, and AR applications. Each key point that is listed is further elaborated upon to provide detail on how they have been incorporated into the designs of mobile media.

- The application design should consider the user's mobility (movement, location and orientation) as the key aspect to establishing a rudimentary link to the presence of the physical environment. This mobility factor is commonly implemented through two approaches: the first being location tracking with GPS sensors, and the second being AR with computer vision techniques.

- The virtual content of the application should consider the variances that are present in physical environment. These variances include aspects such as the weather, time of day and light conditions. Furthermore, in addition to this, the spatial data of the environment such as the boundaries and limits of the space should also be considered when designing any geolocation content.

- The visual graphics of the application should extend beyond the commonly implemented methods of 2D maps and rudimentary 3D visual overlays. Currently, applications augment the physical environment with virtual objects but are generally basic models and virtual signs. In order to further this with more advanced approaches, an exploratory focus on more complete 3D virtual environments should be considered. 
- Another element that should be considered is the concept of connectedness. The location based media applications often had a large number of users in local proximity to each other and social interactions between them often created collaborated efforts in exploring the media. This collaboration was provided through communication functions in the application and helped fostered a community centered around the media experience.

The detailing of these four main points are presented not as a defined checklist criteria, but rather as a set of guidelines for idea and concept development in mobile media design. These guiding elements have been derived from suggested research directions as well as precedent observations, and they have been identified to encourage more consideration of physical elements when designing virtual content in mobile media design. 
Chapter 4 - Design Process 


\section{Design Process}

The following section details the developments of mobile media concepts that were explored during studio practice. These explorations investigated approaches in bridging physical and virtual spaces together for mobile media design so that the disparity would be lessened between them. The applications developed in these explorations were focused on mobile media entertainment and sought to establish enhanced contextual links between physical and virtual elements through the use of AR tracking techniques, 3D graphics and live data integration. 


\section{Defining the Location}

The consideration of location was one of the first decisions made in the design of the mobile application. As highlighted in the criteria, the user's mobility is an important aspect to establishing a rudimentary link between virtual content and a user's physical space. As such for the designs that were developed a location based element needed to exist within it. In determining where this location was based, a number of locations situated in Wellington, New Zealand were considered but it was the Civic Square on Wakefield Street that was eventually chosen as the primary development area. The Civic Square has the significance of being the town center as well as being a social gathering area throughout the day. The enclosed qualities of the square was also well away from any road traffic providing less noise, visual distractions and potentially dangerous areas that mobile devices should not be operated in.

Figure 7. Civic Square - West View.

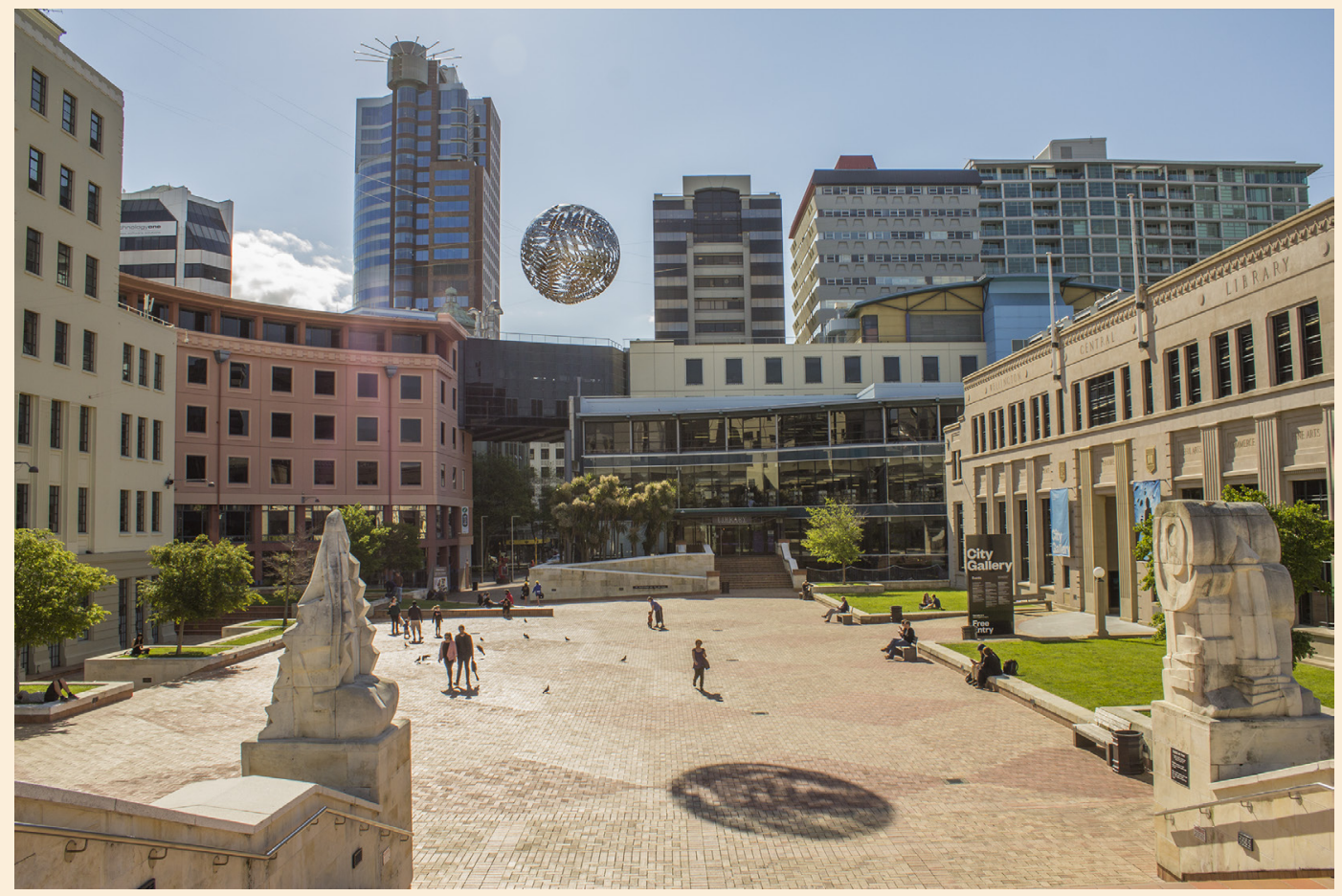




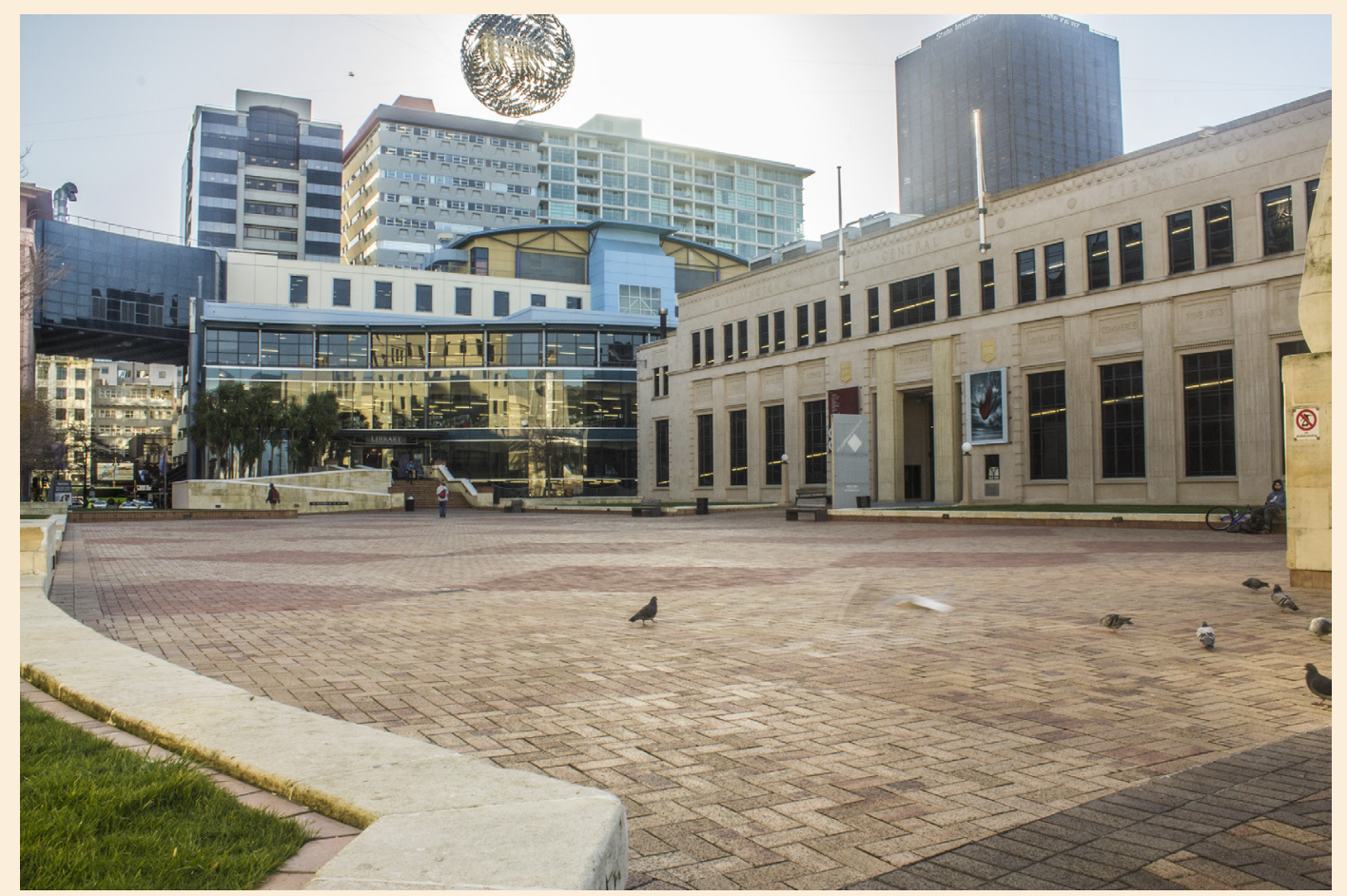

Figure 8.

Civic Square

- North View.

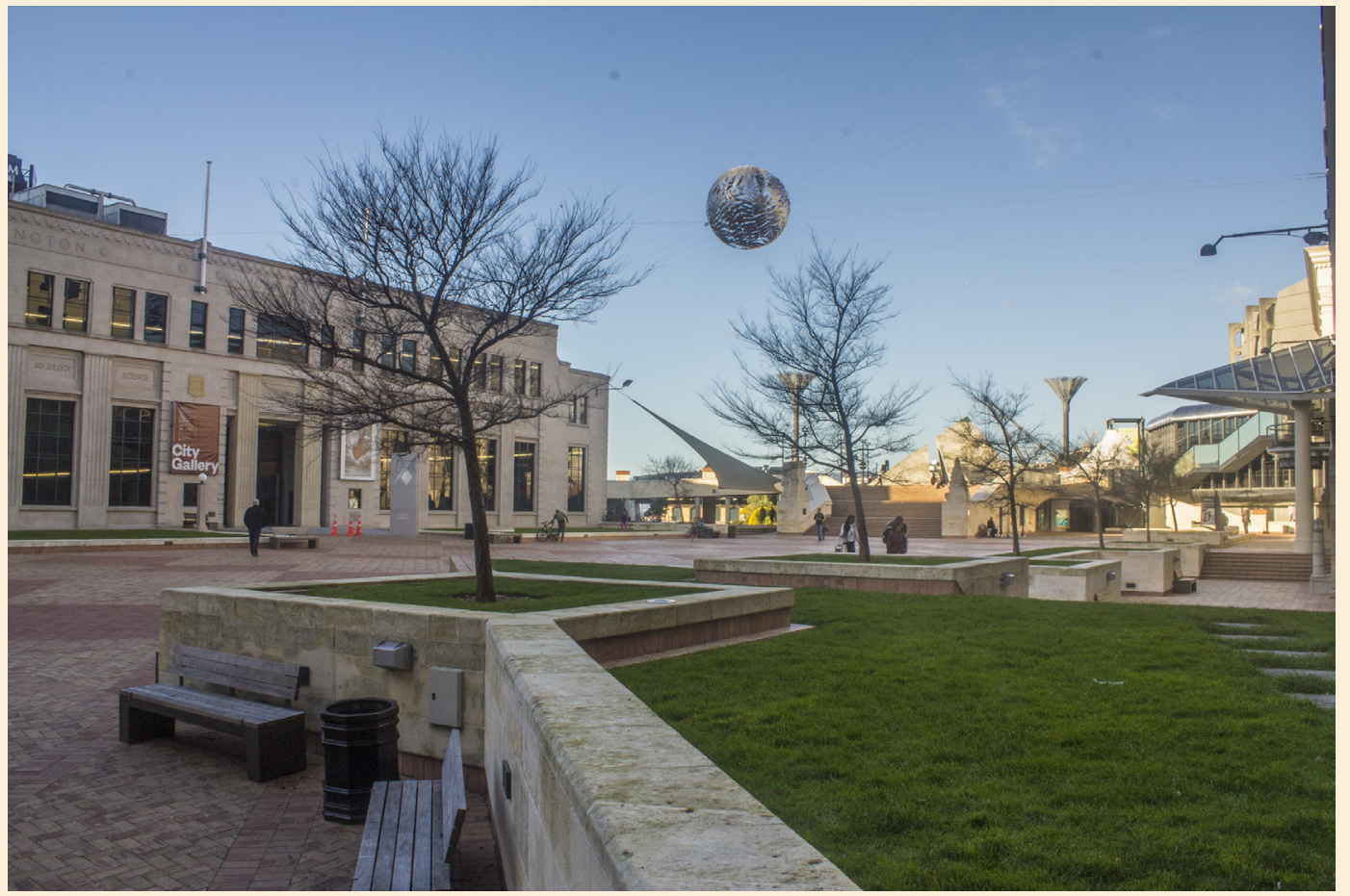

Figure 9.

Civic Square

- East View. 

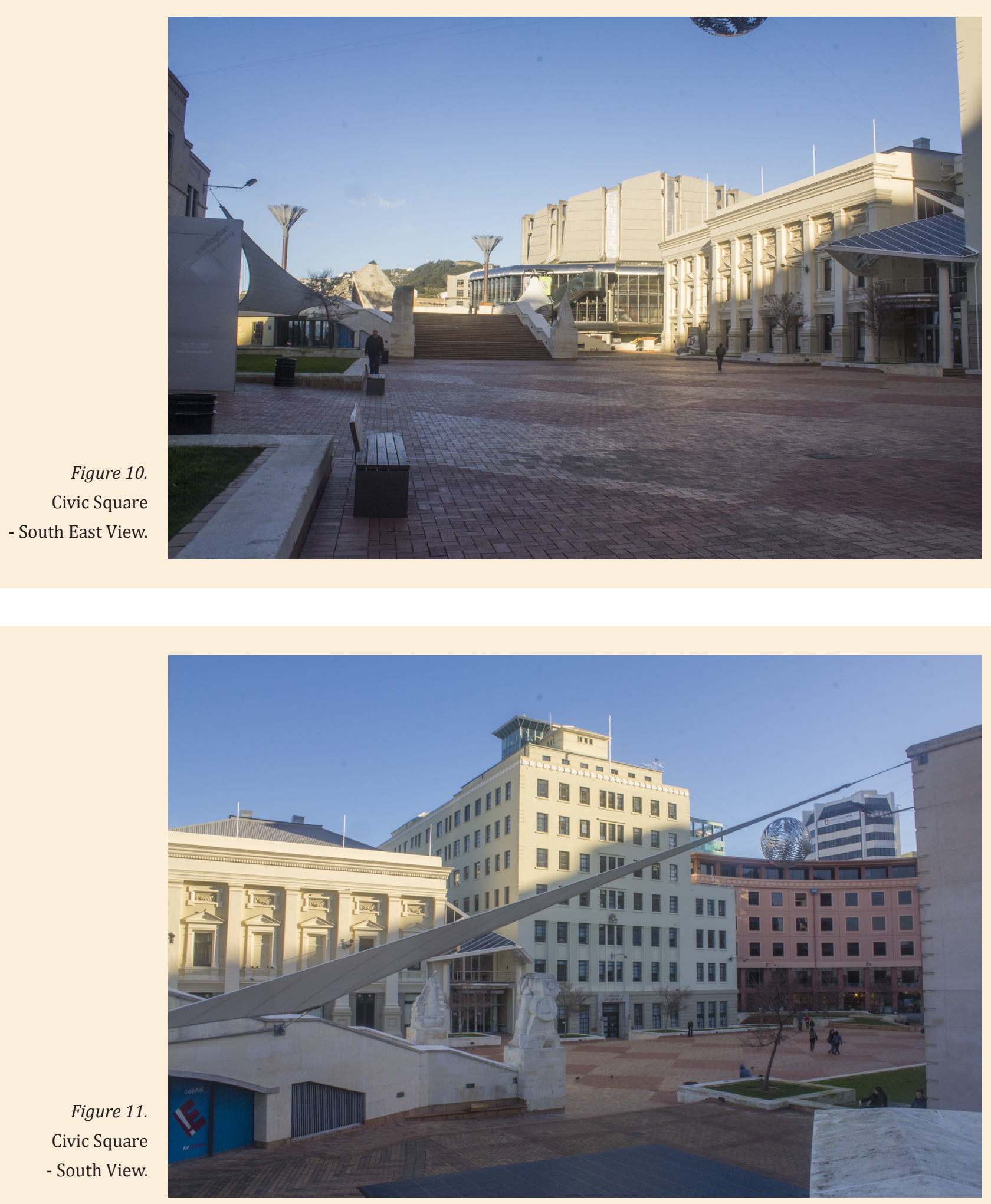


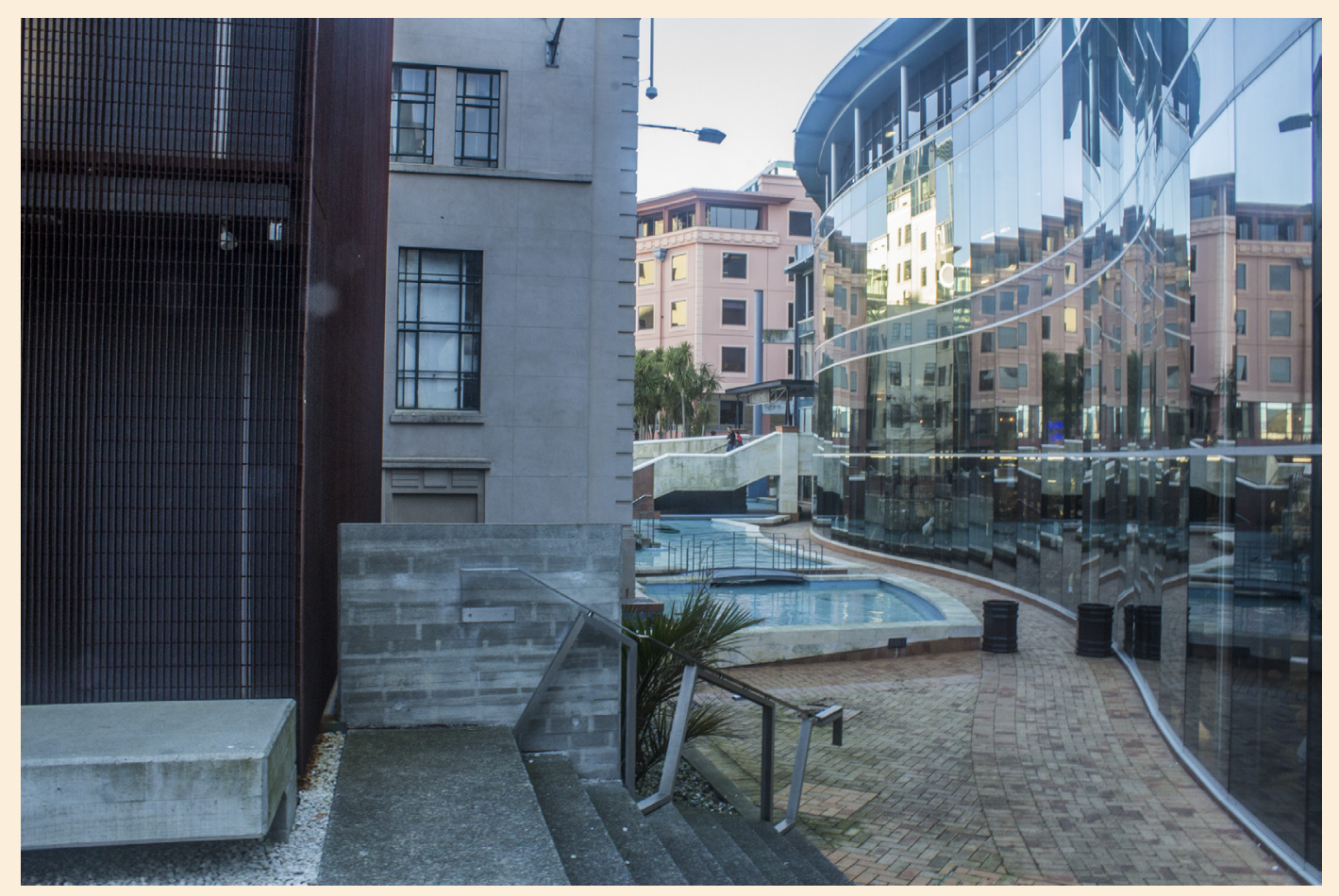

Figure 12.

Civic Square,

- South View:

Library Walkway.

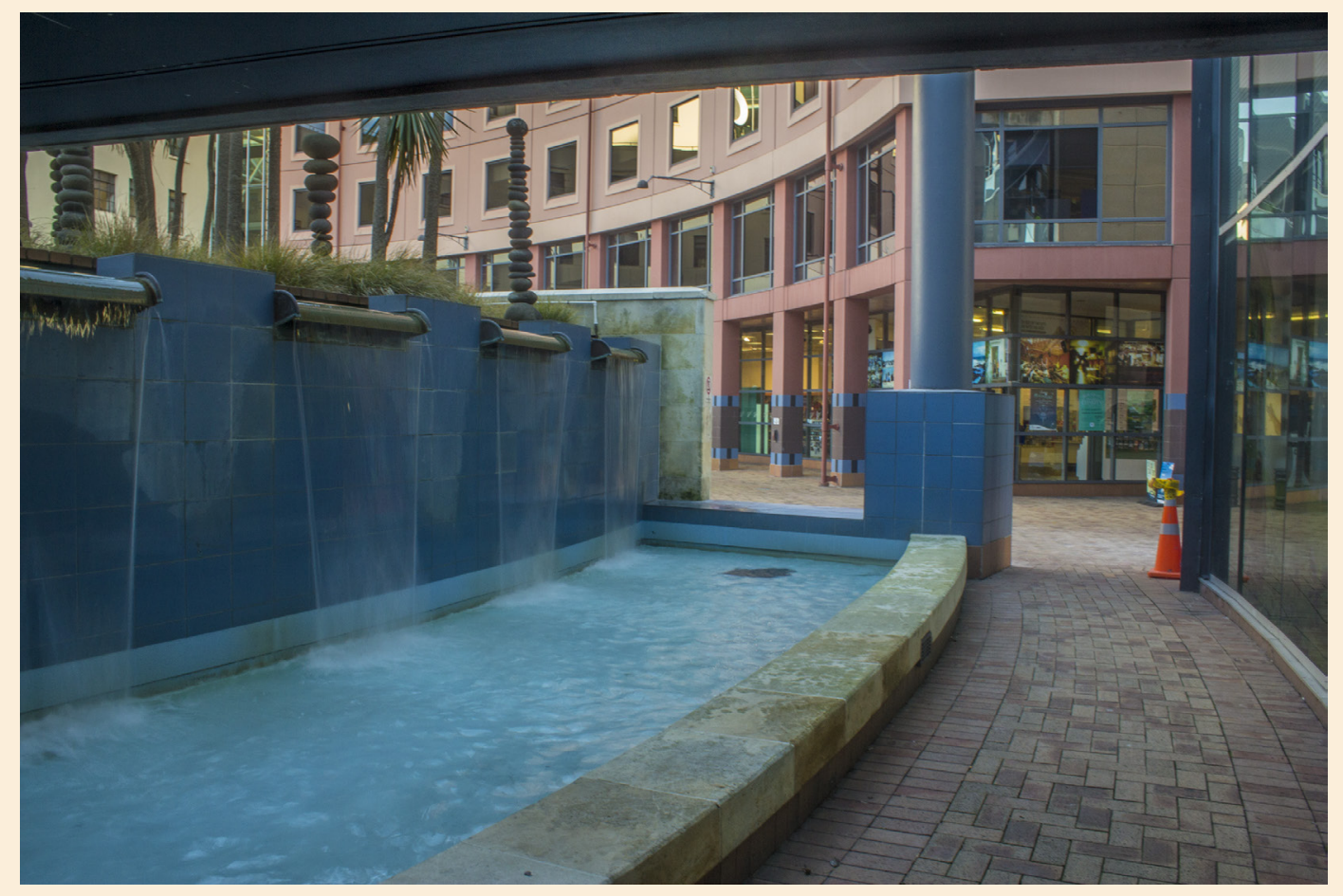

Figure 13.

Civic Square

- South View:

Library walkway

underneath

entrance bridge. 


\section{Linking Physical and Virtual}

In regards to establishing a link between physical and virtual spaces so that there was less disparity of use between them, the virtual elements of the constructed designs were developed in consideration to the physical boundary limits of the buildings and features located within the chosen location (Civic Square). The intent of this was to provide the user with a visual reference to the physical world limits (such as the walls and building facades) and reflect them inside the virtual space of the application. Through doing this, the designs sought to provide viewers with an experience of parallel world where solid and non traversable elements in the physical environment were the same in the virtual mediascape as well.

\section{Live Data Integration}

To further link physical elements into virtual spaces, the constructed designs also incorporated the use of live weather data gathered from various weather stations situated through Wellington City. These weather stations were rapid fire data sources, meaning they updated to an internet API presented at the Weather Underground website (http://www.wunderground.com/weather/api/) close to real time. The weather data included wind information, precipitation, sky conditions and temperature, which was utilised to reflect the current conditions of the physical environment into the virtual space. 


\section{Technical Details}

\section{Development Platform}

The primary development platform chosen for the design explorations was Google Android. While other mobile operating systems existed in the form of Apple's IOS and Microsoft's Windows Phone, the features that were offered between them were the same in terms of hardware capability. The mobile device that was the primary test station and development target was a Sony Xperia Z released in February 2013.

Table 1. Comparison of features in smartphones.

\begin{tabular}{|c|c|c|c|c|c|}
\hline Device & Sony Xperia Z & $\begin{array}{l}\text { Samsung Galaxy } \\
\text { S4 }\end{array}$ & HTC One & Apple iPhone 5C & $\begin{array}{l}\text { Nokia Lumia } \\
1020\end{array}$ \\
\hline os & Android & Android & Android & iOS & Windows \\
\hline Released & Feb 2013 & Apr 2013 & Mar 2013 & Sep 2013 & Jul 2013 \\
\hline \multicolumn{6}{|l|}{ Display } \\
\hline Physical Size & 5.0 inches & 5.0 inches & 4.7 inches & 4.0 inches & 4.5 inches \\
\hline Resolution & $\begin{array}{l}1080 \times 1920 \\
\text { pixels }\end{array}$ & $\begin{array}{l}1080 \times 1920 \\
\text { pixels }\end{array}$ & $\begin{array}{l}1080 \times 1920 \\
\text { pixels }\end{array}$ & $\begin{array}{l}640 \times 1136 \\
\text { pixels }\end{array}$ & $\begin{array}{l}768 \times 1280 \\
\text { pixels }\end{array}$ \\
\hline Features & $\begin{array}{l}\text { Light sensor, } \\
\text { Proximity } \\
\text { sensor, Scratch- } \\
\text { resistant glass } \\
\text { (Dragontrail) }\end{array}$ & $\begin{array}{l}\text { Light sensor, } \\
\text { Proximity } \\
\text { sensor, Scratch- } \\
\text { resistant glass } \\
\text { (Corning Gorilla } \\
\text { Glass 3) }\end{array}$ & $\begin{array}{l}\text { Light sensor, } \\
\text { Proximity } \\
\text { sensor, Scratch- } \\
\text { resistant glass } \\
\text { (Corning Gorilla } \\
\text { Glass) }\end{array}$ & $\begin{array}{l}\text { Light sensor, } \\
\text { Proximity } \\
\text { sensor, } \\
\text { Oleophobic } \\
\text { coating }\end{array}$ & $\begin{array}{l}\text { Light sensor, } \\
\text { Proximity } \\
\text { sensor, Scratch- } \\
\text { resistant glass } \\
\text { (Corning } \\
\text { Gorilla Glass 3), } \\
\text { Polarizing filter }\end{array}$ \\
\hline Camera & 13.1 Megapixels & 13 Megapixels & 4 Megapixels & 8 Megapixels & 41 Megapixels \\
\hline GPS & $\begin{array}{l}\text { GPS, A-GPS, } \\
\text { Glonass }\end{array}$ & $\begin{array}{l}\text { GPS, A-GPS, } \\
\text { Glonass }\end{array}$ & $\begin{array}{l}\text { GPS, A-GPS, } \\
\text { Glonass }\end{array}$ & $\begin{array}{l}\text { GPS, A-GPS, } \\
\text { Glonass, Cell } \\
\text { ID, Wi-Fi } \\
\text { positioning }\end{array}$ & $\begin{array}{l}\text { GPS, A-GPS, } \\
\text { S-GPS, Glonass, } \\
\text { Cell ID, Wi-Fi } \\
\text { positioning }\end{array}$ \\
\hline WiFi & $\begin{array}{l}802.11 \mathrm{a}, \mathrm{b}, \mathrm{g}, \mathrm{n}, \\
\mathrm{n} 5 \mathrm{GHz}\end{array}$ & $\begin{array}{l}802.11 \mathrm{a}, \mathrm{b}, \mathrm{g}, \mathrm{n}, \\
\mathrm{n} 5 \mathrm{GHz}, \mathrm{ac}\end{array}$ & $\begin{array}{l}802.11 \mathrm{a}, \mathrm{b}, \mathrm{g}, \mathrm{n}, \\
\mathrm{n} 5 \mathrm{GHz}, \mathrm{ac}\end{array}$ & $\begin{array}{l}802.11 \mathrm{a}, \mathrm{b}, \mathrm{g}, \mathrm{n}, \\
\mathrm{n} 5 \mathrm{GHz}\end{array}$ & $802.11 \mathrm{a}, \mathrm{b}, \mathrm{g}, \mathrm{n}$ \\
\hline Sensors & $\begin{array}{l}\text { Accelerometer, } \\
\text { Gyroscope, } \\
\text { Compass }\end{array}$ & $\begin{array}{l}\text { Accelerometer, } \\
\text { Gyroscope, } \\
\text { Compass, } \\
\text { Thermometer, } \\
\text { Gesture, } \\
\text { Humidity, } \\
\text { Barometer }\end{array}$ & $\begin{array}{l}\text { Accelerometer, } \\
\text { Gyroscope, } \\
\text { Compass }\end{array}$ & $\begin{array}{l}\text { Accelerometer, } \\
\text { Gyroscope, } \\
\text { Compass }\end{array}$ & $\begin{array}{l}\text { Accelerometer, } \\
\text { Gyroscope, } \\
\text { Compass, } \\
\text { Barometer }\end{array}$ \\
\hline
\end{tabular}

Note: Data for Sony Xperia Z is from Sony Xperia Z specs (2013); Data for Samsung Galaxy S4 is from Samsung Galaxy S4 specs (2013); Data for HTC One is from HTC One specs (2013); Data for Apple iPhone 5C is from Apple iPhone 5c specs. (2013); And Data for Nokia Lumia 1020 is from Nokia Lumia 1020 specs (2013). 


\section{Hardware Features}

The key technologies that were utilised in the developments are presented below and are commonly found as a standard set of features in mobile devices today.

- GPS

- WiFi and 3G/4G Mobile internet

- Camera

- Sensors

- Accelerometer

- Gyroscope

- Magnetometer (Compass)

The GPS and WiFi was used to determine the physical world position by drawing data from satellites and cell towers. This positioning information was used to ensure the correct virtual content was displayed for the corresponding physical area. This tracking was further enhanced by the three sensors combined through a software concept called sensor fusion. The sensor fusion implementation allowed for enhanced movement and orientation tracking. The combination of these tracking elements enabled an accurate AR camera control, which allowed for the mobile device to be controlled as a window to a virtual space. The virtual content that would be seen in this 'window' would align up with the physical space as redefined virtual elements. 


\section{Design - Initial: Extinct NZ Birds}

\section{Description}

This preliminary concept that was explored had a more educational focus on presenting an experience that brought extinct historical New Zealand animals back to life with Augmented Reality. It sought to present an immersive 3D virtual world where the extinct birds would live and interact in an animated media space.

This concept sought to present two large birds identifiable to NZ history - the Giant Moa and the Haast Eagle. The Giant Moa was a flightless bird and was the primary herbivore in historical NZ. It stood at around 2 metres at it's back, and 3 metres with its neck fully stretched upward. In contrast, the Haast Eagle was the primary predator; a raptor that varied between 1-1.5 metres in length. Its wingspan could also potentially grow to reach 3 metres making it the largest eagle known to have existed.
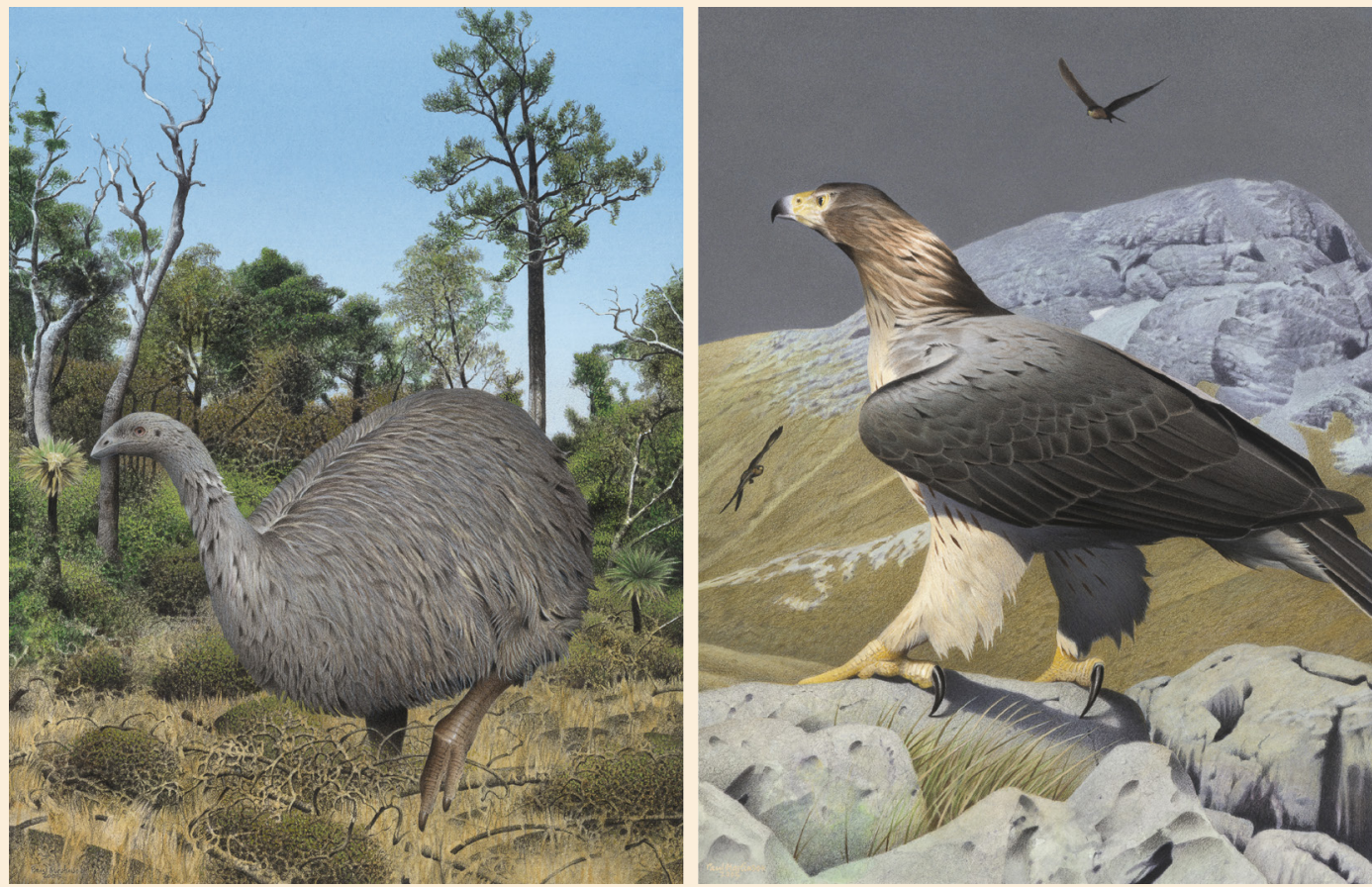

Figure 14-15.

Left: Eastern Moa. Emeus crassus. (2005). Retreived under CC BY-NC-ND 3.0 NZ.

Right: Haast's Eagle. Harpagornis moorei. (2005). Retreived under CC BY-NC-ND $3.0 \mathrm{NZ}$. 


\section{Development}

This initial design was developed using a 3D modelling program called Blender and was deployed on web technologies, specifically using a web server backend and WebGL (a 3D graphics API). What this deployment setup enabled was ease of access and cross platform compatibility. The common web browsers today all have WebGL compatibility and since the application was deployed online, the differences between development languages on operating systems could be bypassed in favour of a generic web language. This setup also had the added benefit of not requiring users to install additional software to their devices.

Figure 16-17. Development images of Moa and Haast Eagle.
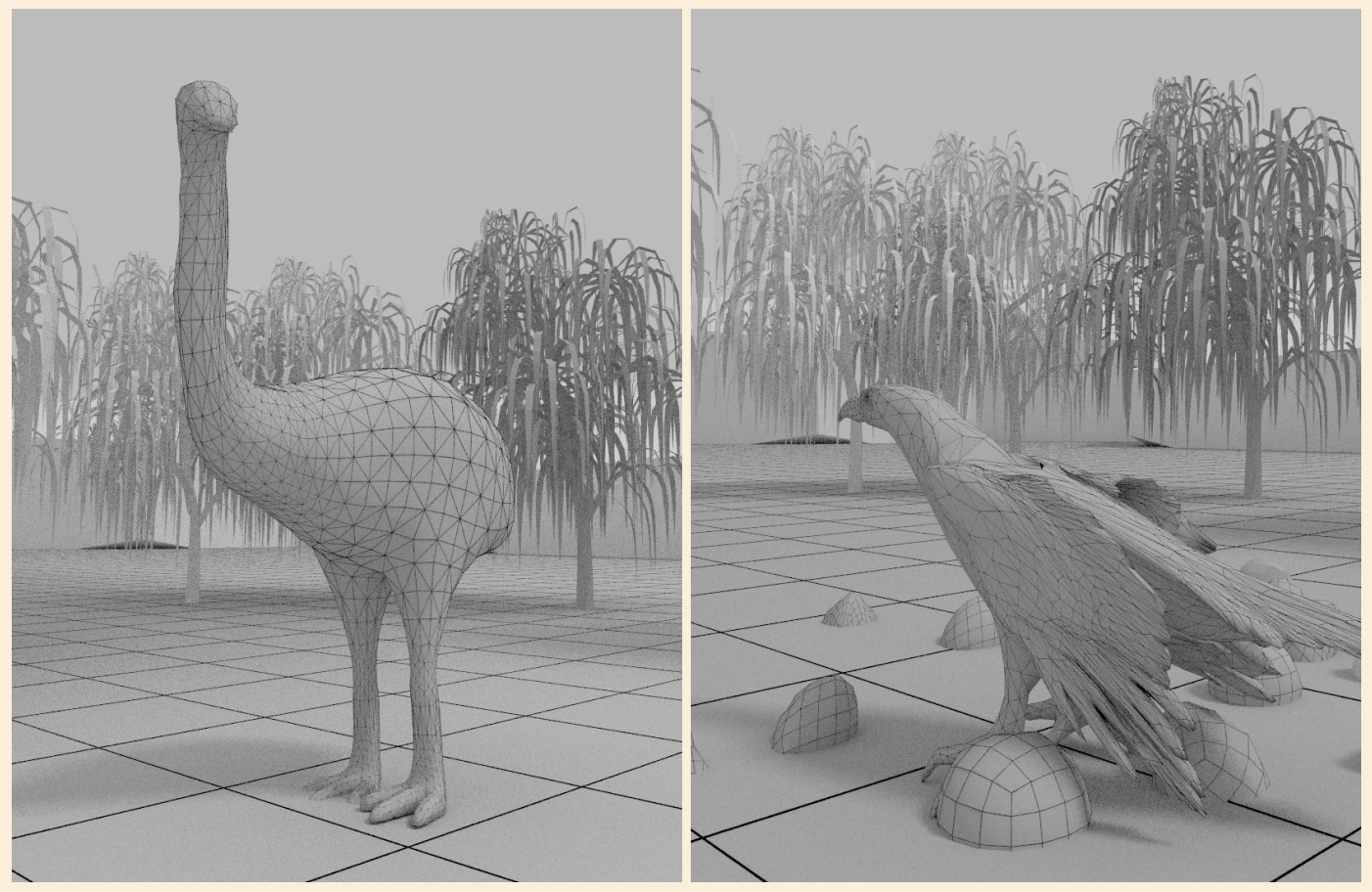


\section{Visual Implementation}

The implementation of the graphics was primarily 3D as the overall concept was presenting an AR environment with historical NZ birds in a natural habitat. To extend beyond the implementations that have been commonly found in AR applications however, the idea in this concept was to create a more immersive virtual environment that completely redefined the physical environment. Instead of just aligning $3 \mathrm{~d}$ virtual models to tracked areas of space, the virtual environment was designed to encompass a full 360 degree view so that the user could physically look around with their mobile device as if viewing the virtual environment through a small window.

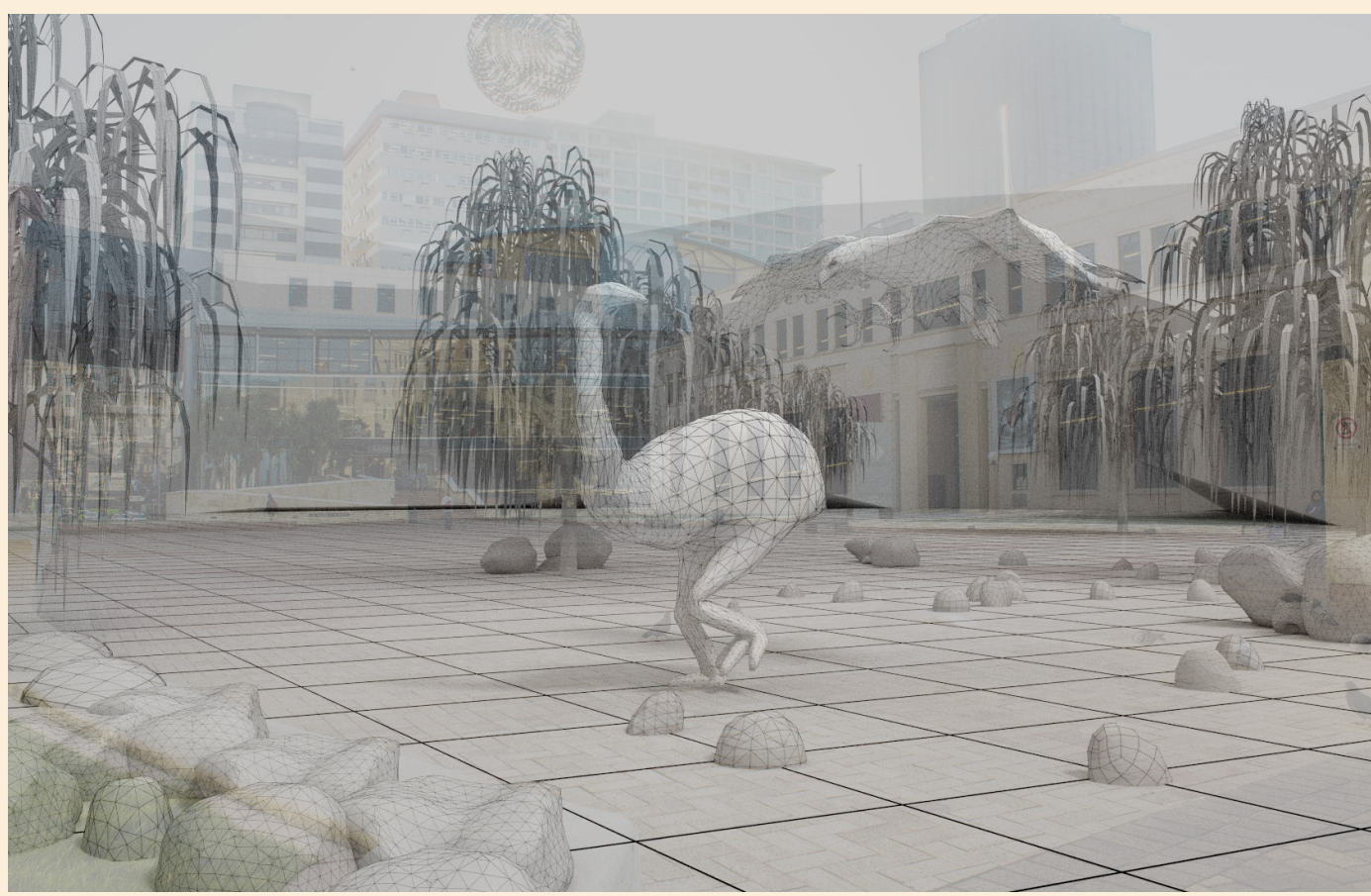

Figure 18.

Development image composed onto a photo of

Civic Square. 

Screen Renders of Haast Eagle hunting a Moa

- Front view.

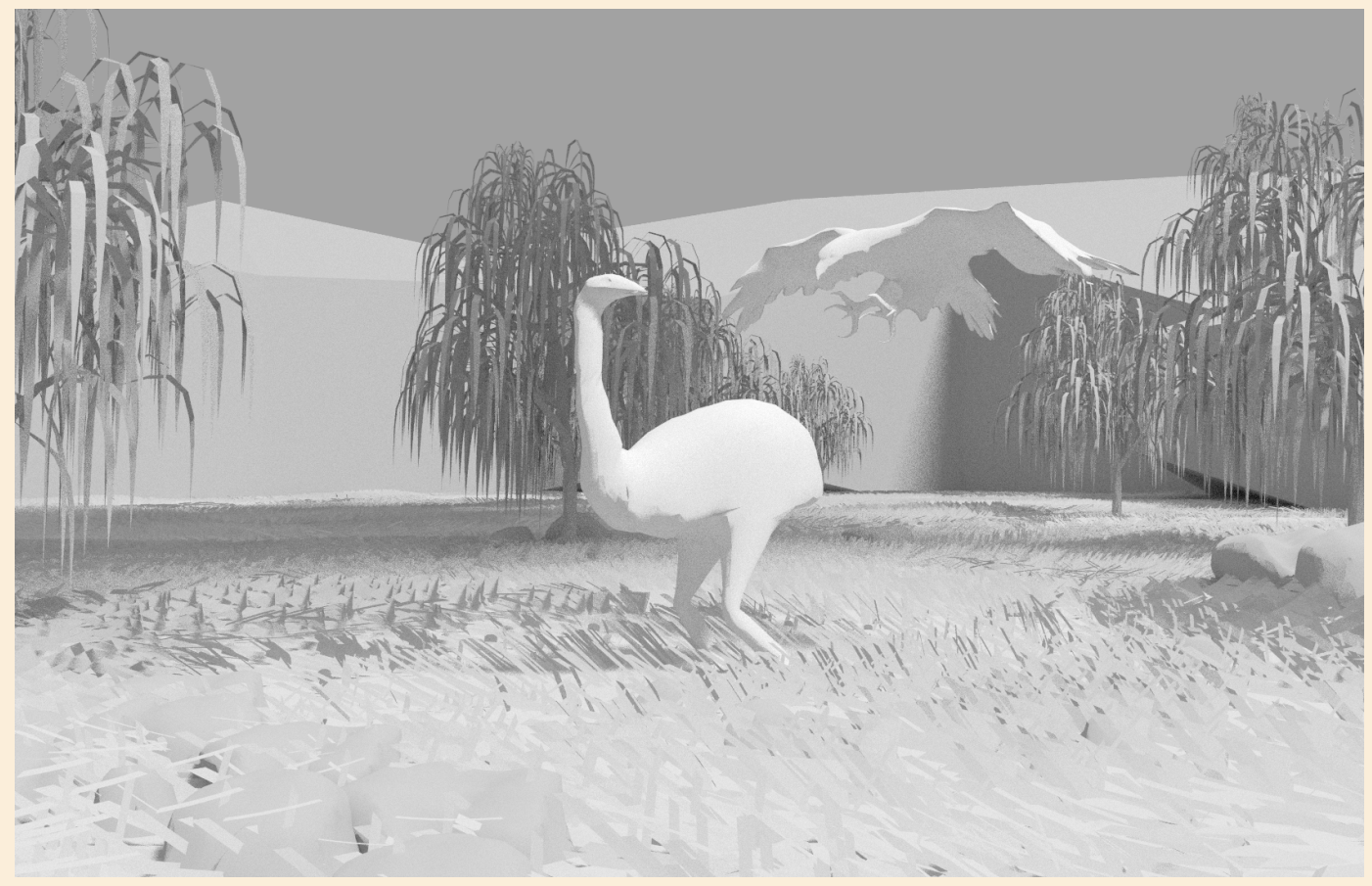

Figure 20.

Screen Renders

of Haast Eagle

hunting a Moa

- Top view.

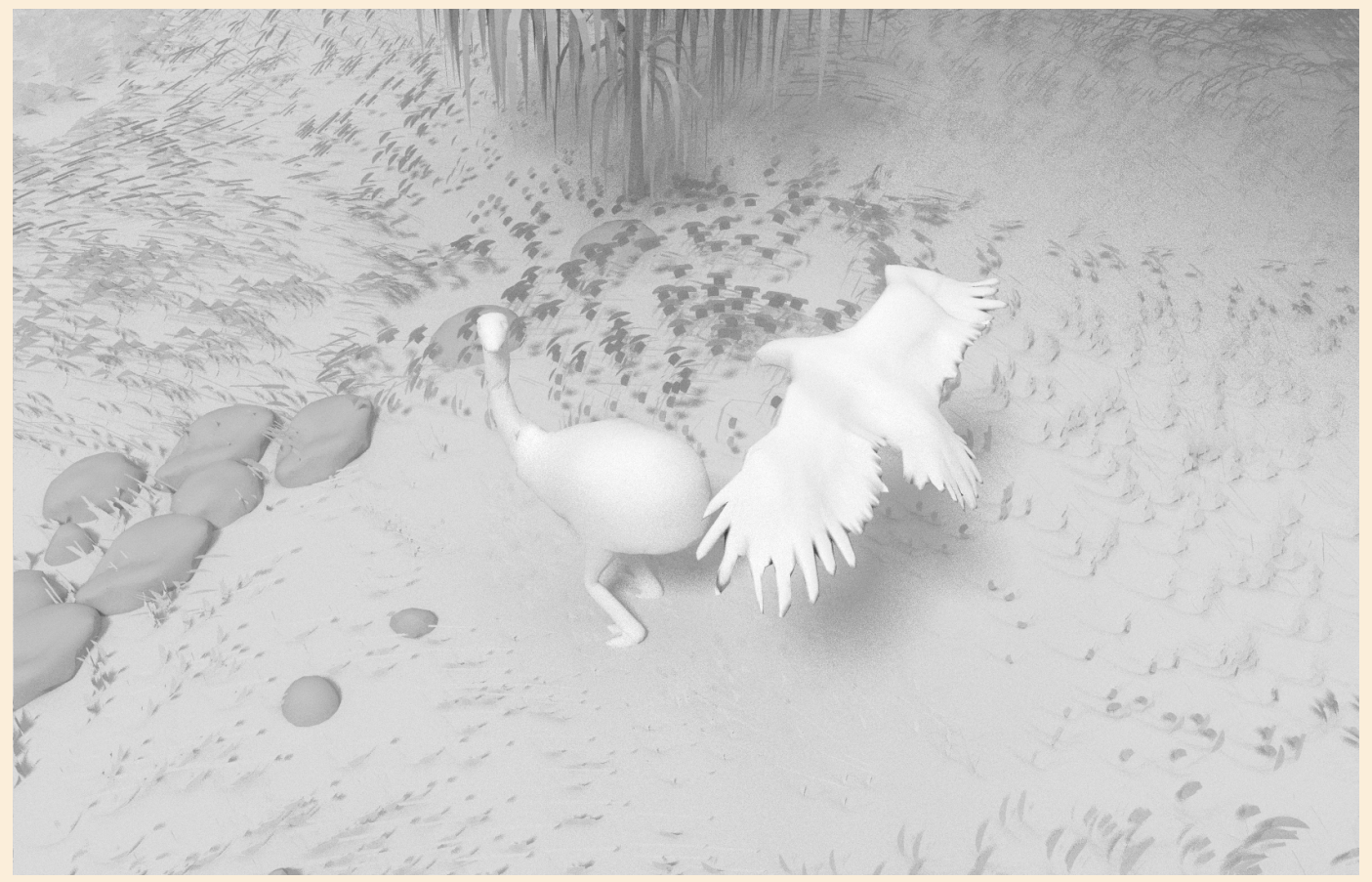




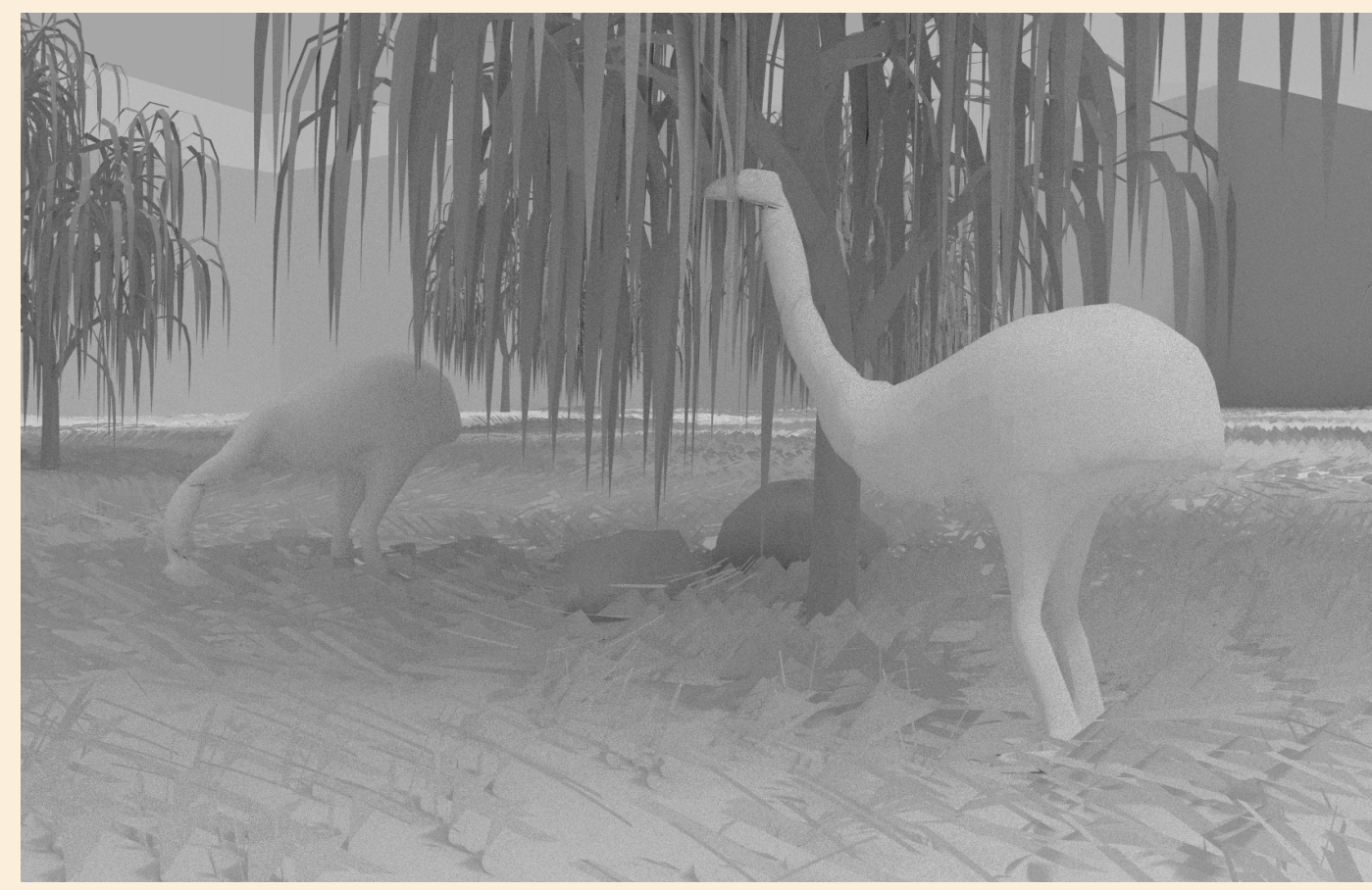

Figure 21.

Screen Render

of two Moas.

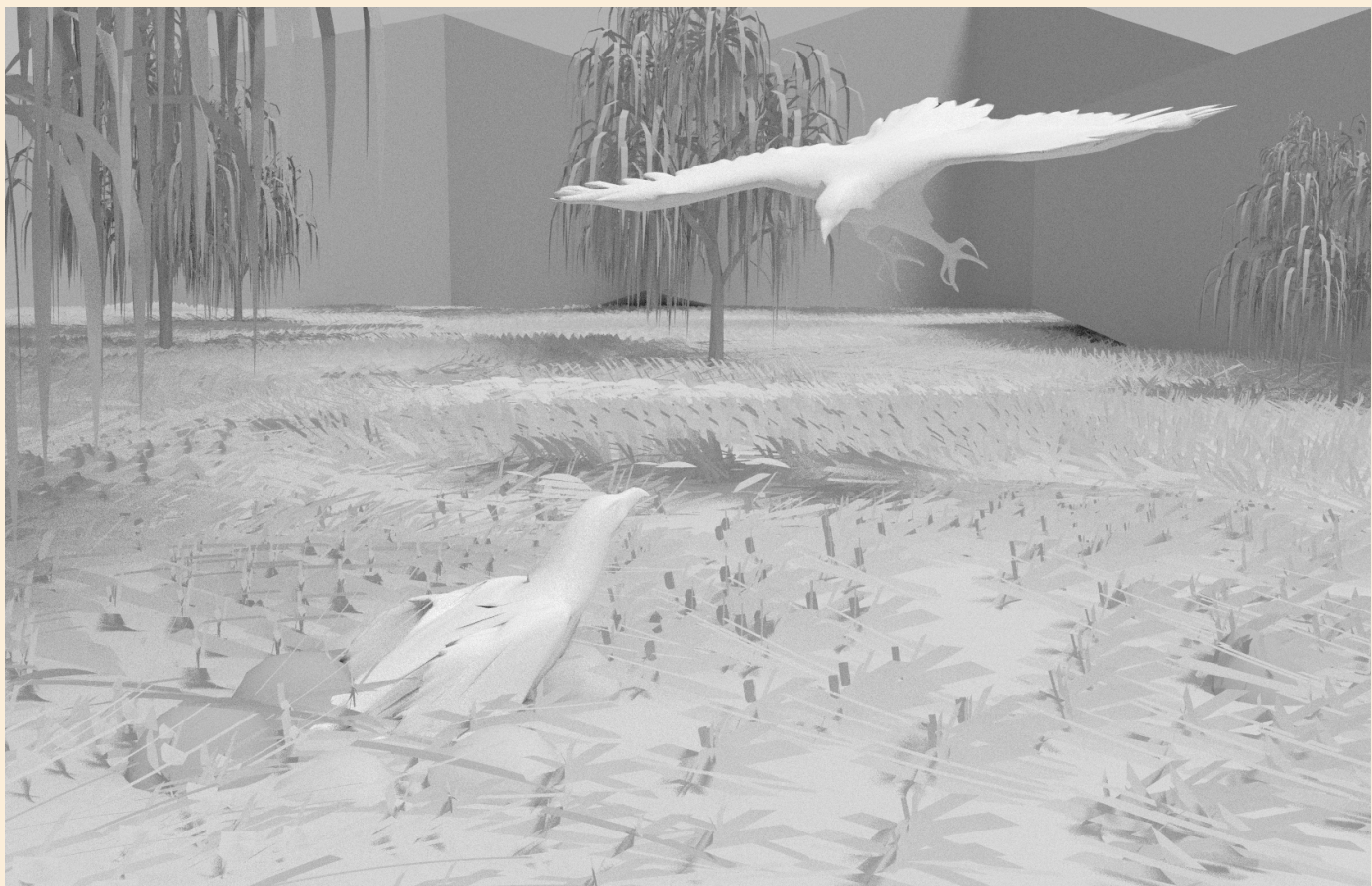

Figure 22.

Screen render

of a Haast

Eagle pair. 


\section{Evaluation}

The development of this concept enabled explorations into the current capabilities of mobile hardware. It also highlighted the design aspects of virtual content that needed to be considered more if an establishing link was to be made between physical and virtual spaces.

One of the initial tests in starting development was to confirm how well orientation and location tracking could be performed on the mobile test device. This type of tracking relied on the accelerometer and magnetometer sensors and were tested in a sensor fusion implementation. Sensor fusion refers to combining sensor data from multiple sources to provide a more accurate result. A level of accuracy was needed because the fundamental design of this concept was to create a virtual space that was tracked to the user's surrounding physical space. If the sensors were not accurate enough then the intent to use the orientation and positioning data to control the virtual camera of a virtual space would not prove successful. This would be because the interface user control would still display a level of disparity between the physical environment and virtual space as the content would not register and align correctly.

In the test of the orientation and location tracking, the results proved responsive and virtual elements could be tracked in real time with not much noticeable screen lag. However this performance degraded when a large amount of 3D virtual elements were displayed on screen. The main issue that affected the performance was generally tied to the quality of the 3D models that were displayed. As such, the $3 \mathrm{~d}$ assets that were produced for the application were optimised in terms of polygon count and texture resolution to ensure the application ran as smooth as it possibly could. 
Another area found to have needed more refinement during development was the required internet connection to access the application. While the linkage of live weather data was successful and provided a dynamic influence in linking the physical conditions of Wellington City to the virtual environment, it was discovered that the city's WiFi coverage was rather poor, and the connection was often too unstable to provide a timely response when accessing the application. To ensure that a disconnection would not completely stop the application, the deployment platform was migrated from the web browser and developed as a native android app. What this allowed was an offline component that user's could still operate if the connection was lost. However, one downside to this was that a lost connection would mean that the weather dynamics would not update until the connection was re-established.

One final detail to be highlighted is the design of the virtual content. While the intent of the application was to create a mediascape that displayed two extinct NZ birds in a linked physical to virtual environment, the challenge came from displaying them in a manner where they were not just another virtual AR signpost. As this concept was mainly envisioned to reduced the disparity between physical and virtual spaces, this mediascape needed to 'feel' like it existed in a parallel space to the user. However, although this concept aimed to achieve this by utilising the limits of the physical world in the design of the virtual space, what became apparent was that the virtual environment design did not reflect the natural habitat that the birds had lived in, making it seem a bit out of place. To resolve this, the design of the virtual environment needed to developed in a coherent manner to the scenario setting as well as the physical limits of the surrounding world. 


\section{Summary}

The design presented in this section envisioned a scenario that focused on bringing two of New Zealand's extinct bird's back to life through a mobile media application. The concept was designed with consideration to the elements identified in a design criteria which was constructed by analysing theoretical discussions and precedent works in lessening the disparity between physical and virtual space usage. Those elements were explored during the development of the concept and applied as core aspects of the resulting media application. However, in evaluating the application, it was found that some designed features and decisions needed to be reconsidered as the challenges they provided would draw away from the intended goal of providing a media application that user's could experience across physical and virtual spaces.

It should also be noted that despite the challenges that were highlighted, this design is by no means an unsuccessful application. The premise of this design offers many interesting elements that can be explored further by developers to present different messages and scenarios for viewers. The approaches taken in the development of this application such as designing the virtual content to physical world boundaries and linking physical data into the environment, provides for a more unique approach in creating a user experience space. This opens up a myriad of possible application scenarios that do not necessarily have to be realistic or educational in nature. For instance, this application could investigate the extinct NZ birds in a modern context, exploring how the birds may live in the presence of 21st century technology and cities. Imagine what it would be like to have to be wary of Haast Eagles in today time. This possibility for fictitious or speculative scenarios existing as parallel spaces in the urban city would provide an interesting take on the perception of space. Effectively, with current technologies in Augmented Urban spaces, the urban city could be redefined to an individual's imagination. 


\section{Design - Revised: Echoes}

\section{Description}

This revised design sought to explore not the grand vision of a complex media experience but rather the virtual environment design and the visual quality that could be achieved.

This application was created in a similar manner to the previous concept. The assets in the virtual environment wered designed with consideration to the limits and boundaries of Civic square. The live data integrations offered the dynamic atmosphere conditions and the mobility tracking on the mobile devices enabled users to physically move about the environment to explore the virtual one.

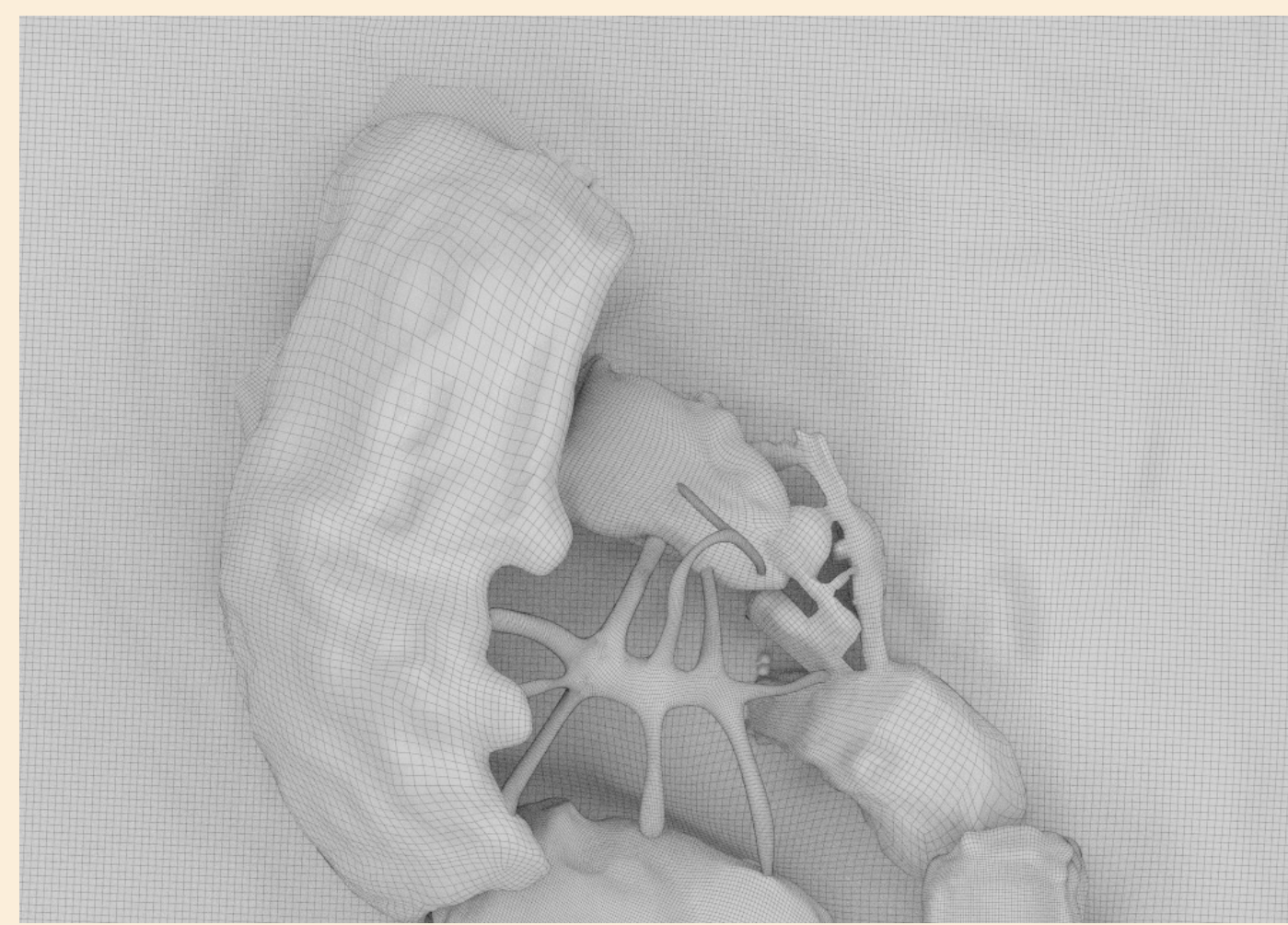

Figure 23.

Development still composed onto a satellite Google maps image. 


\section{Development}

Echoes was also developed using Blender as the primary $3 \mathrm{~d}$ modelling tool. The models created in this software were imported into a 3D game engine called Unity. The Unity game engine was utilised because it offered a complete 3D package to control and display virtual content. The capabilities of the engine also allowed a more optimised codebase to be implemented for the user camera control which improved the overall accuracy of the orientation and position tracking.

Figure 24-25.

Echoes

Development

images.

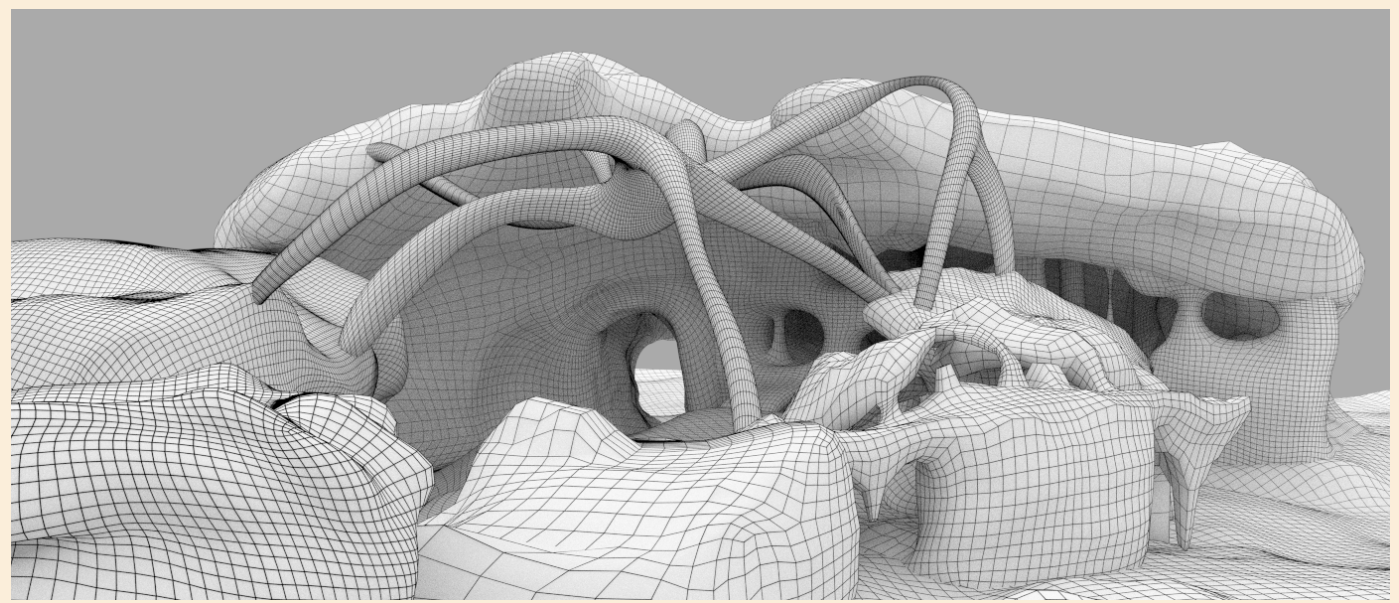




\section{Redefining Civic Square}

The virtual environment developed for this revised design 'Echoes' was a rock and cave formation which drew inspiration from the Civic Square itself. The Civic Square being the town center of Wellington city is generally a place for people to walk to and gather throughout the day. The square is also surrounded by buildings that visually shields away most of the busy road traffic. This retreat like quality reflects to the idea that in ancient times, caves were used as retreats away from the dangers of the outside world.

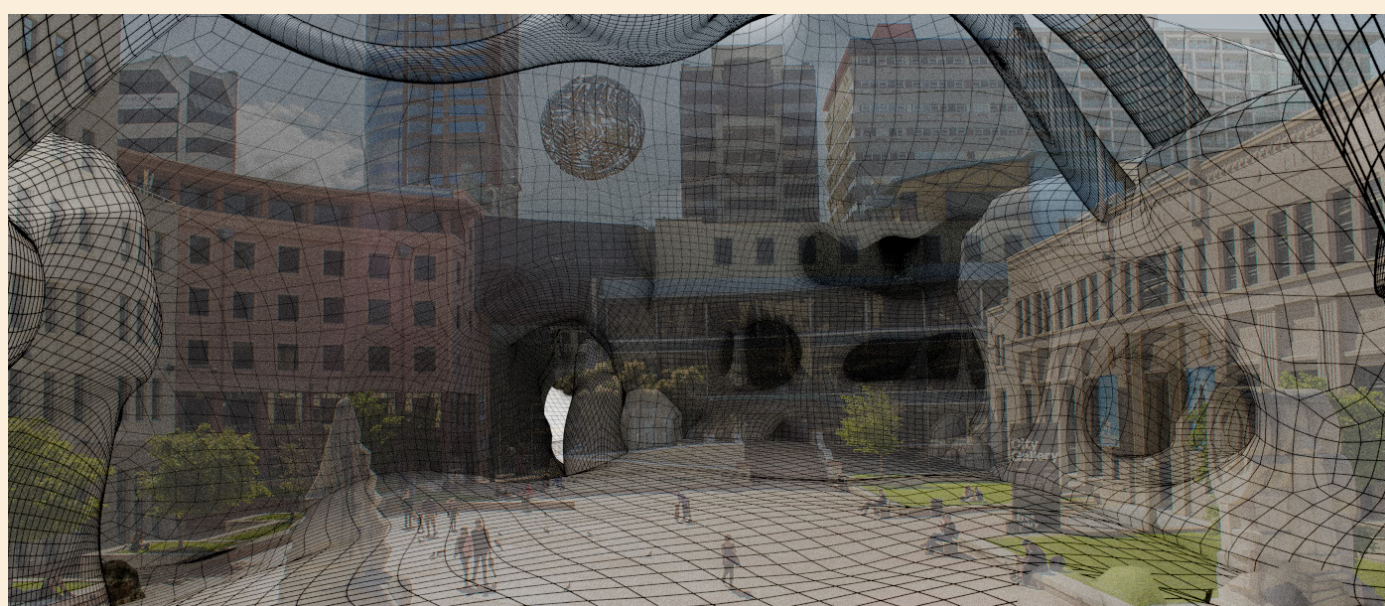

Figure 26-27. Development stills composed onto photos of Civic Square.

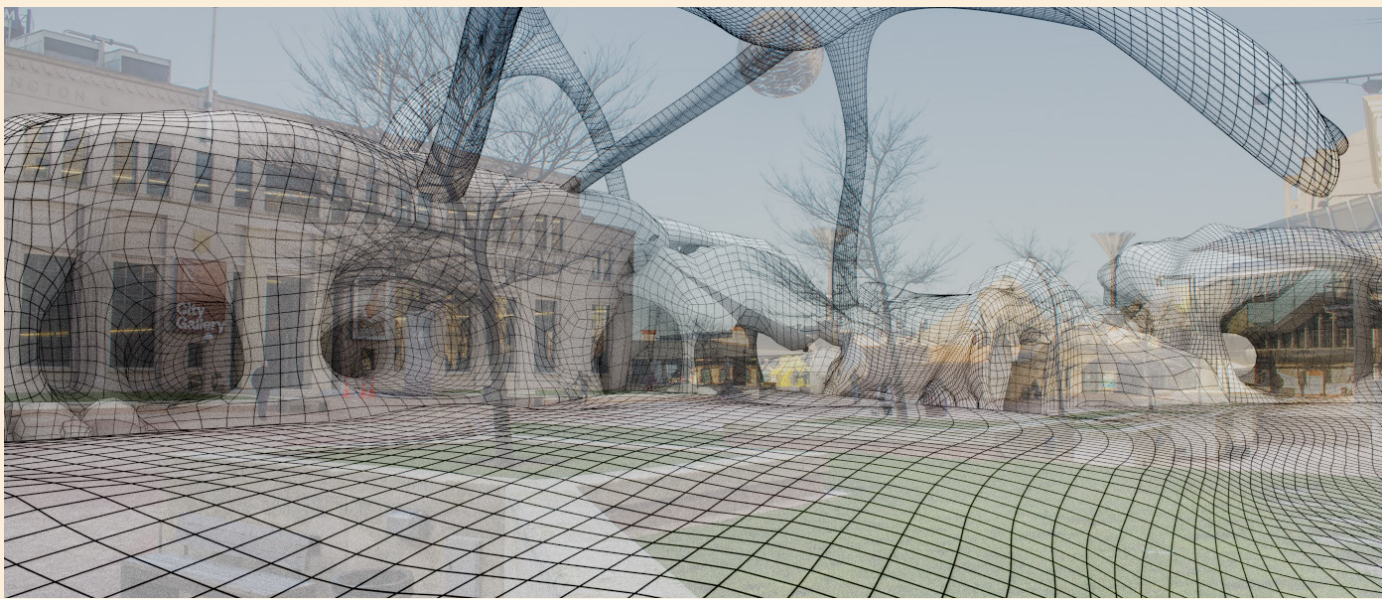




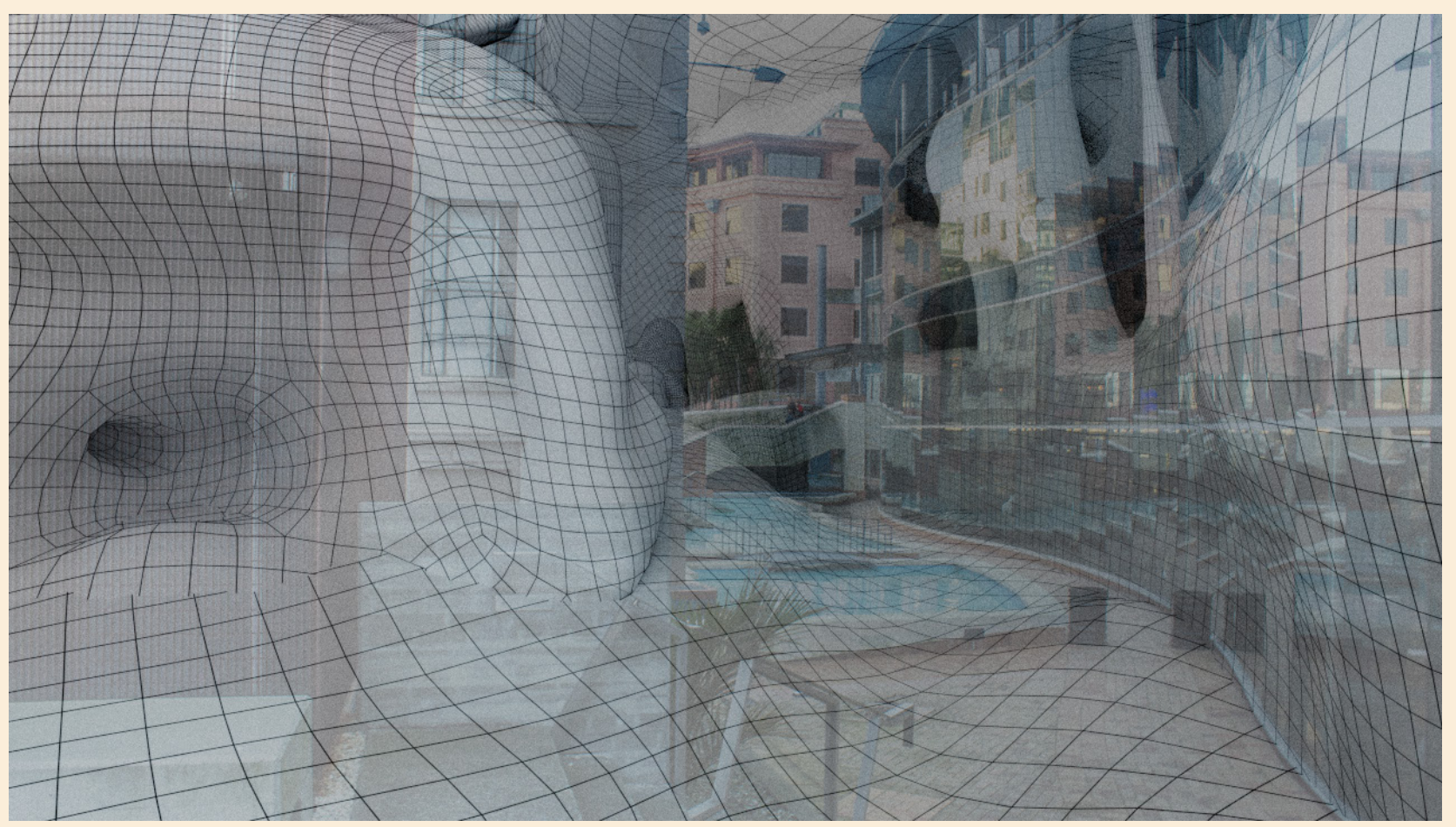

Figure 28.

Above: Development image composited onto Civic Square.

Figure 29-30.

Opposite Page: Images detailing how the media application is viewed. 

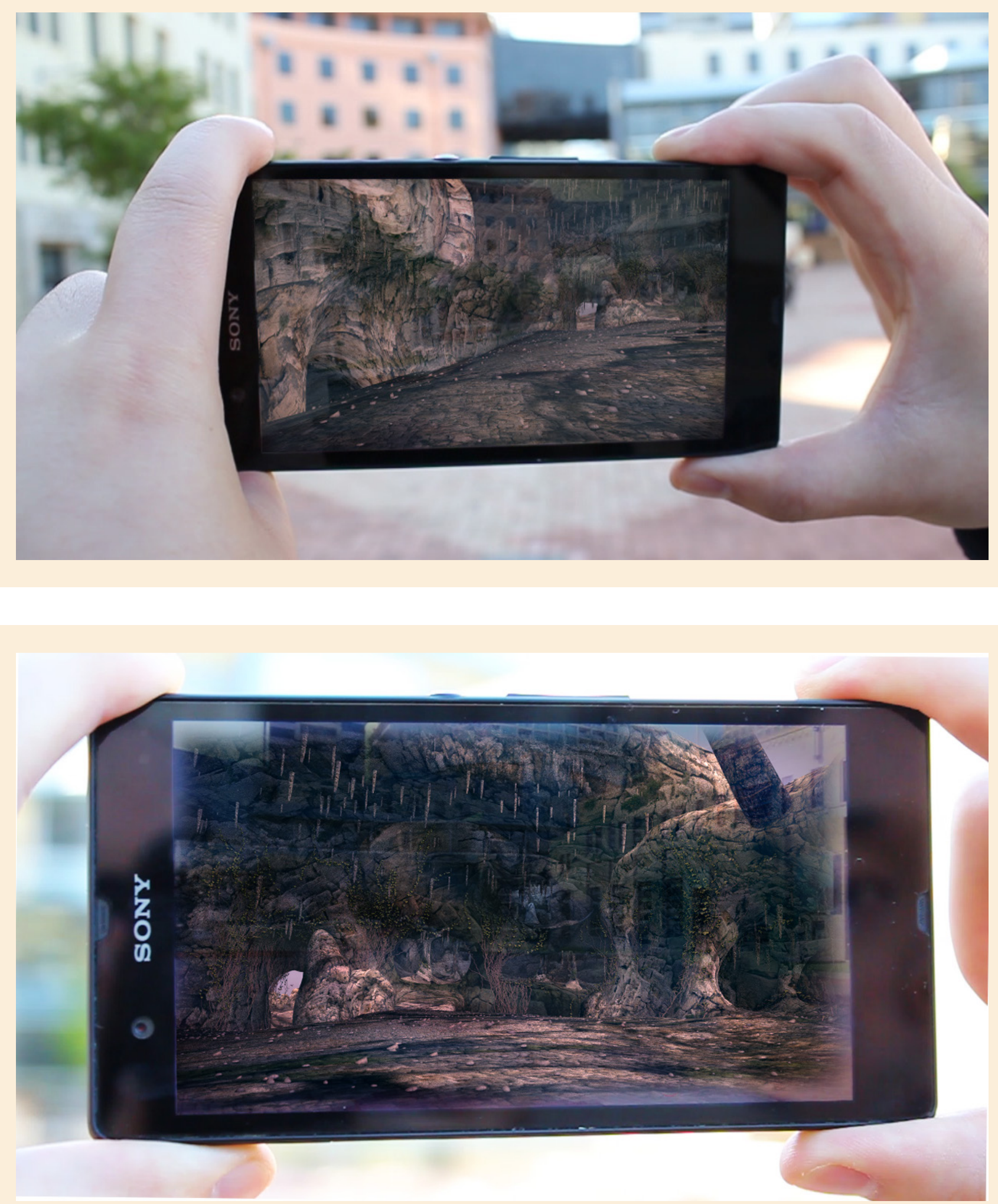
Figure 31-32. Screen renders of environment in Echoes application.
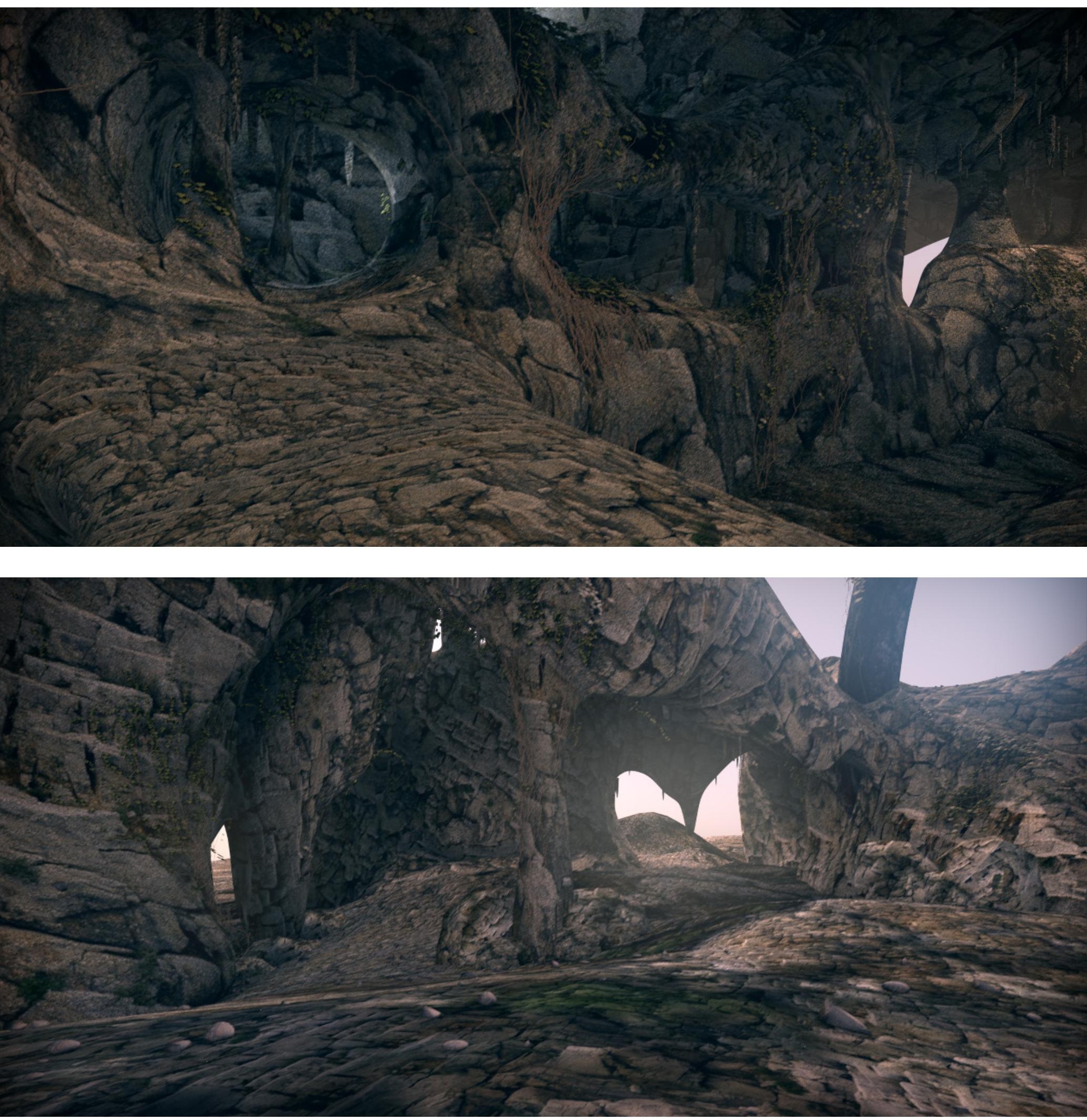
Figure 33-34 Screen renders of environment in Echoes application.
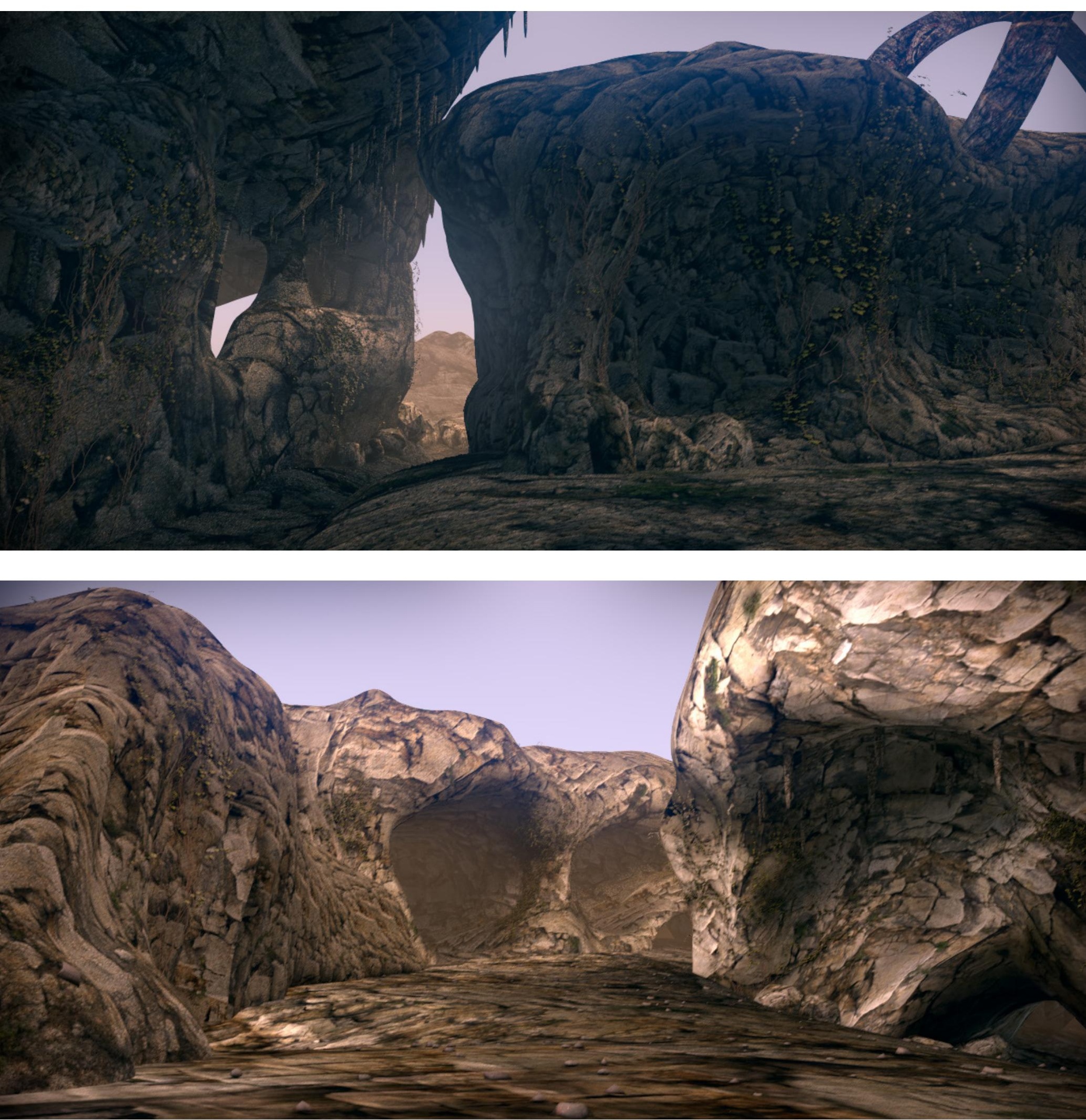


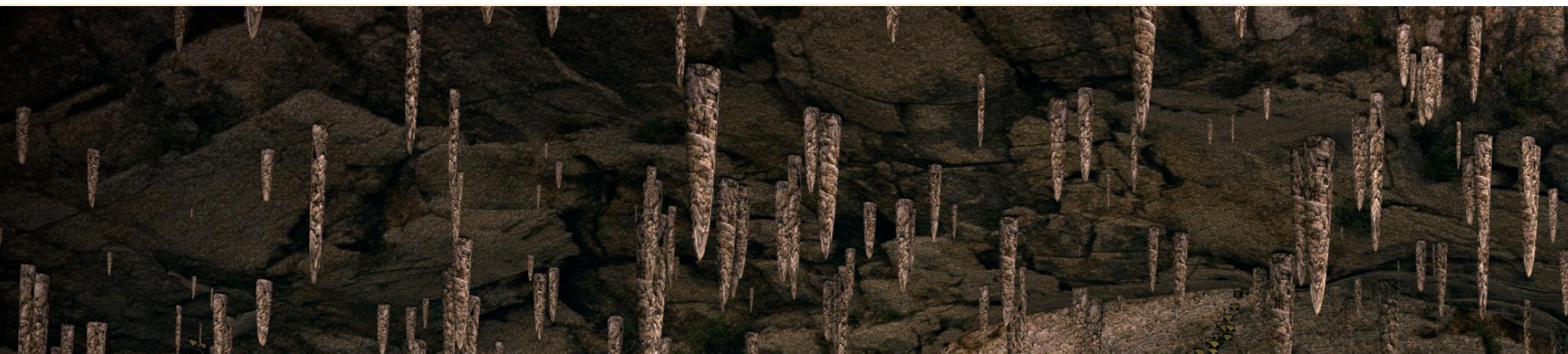




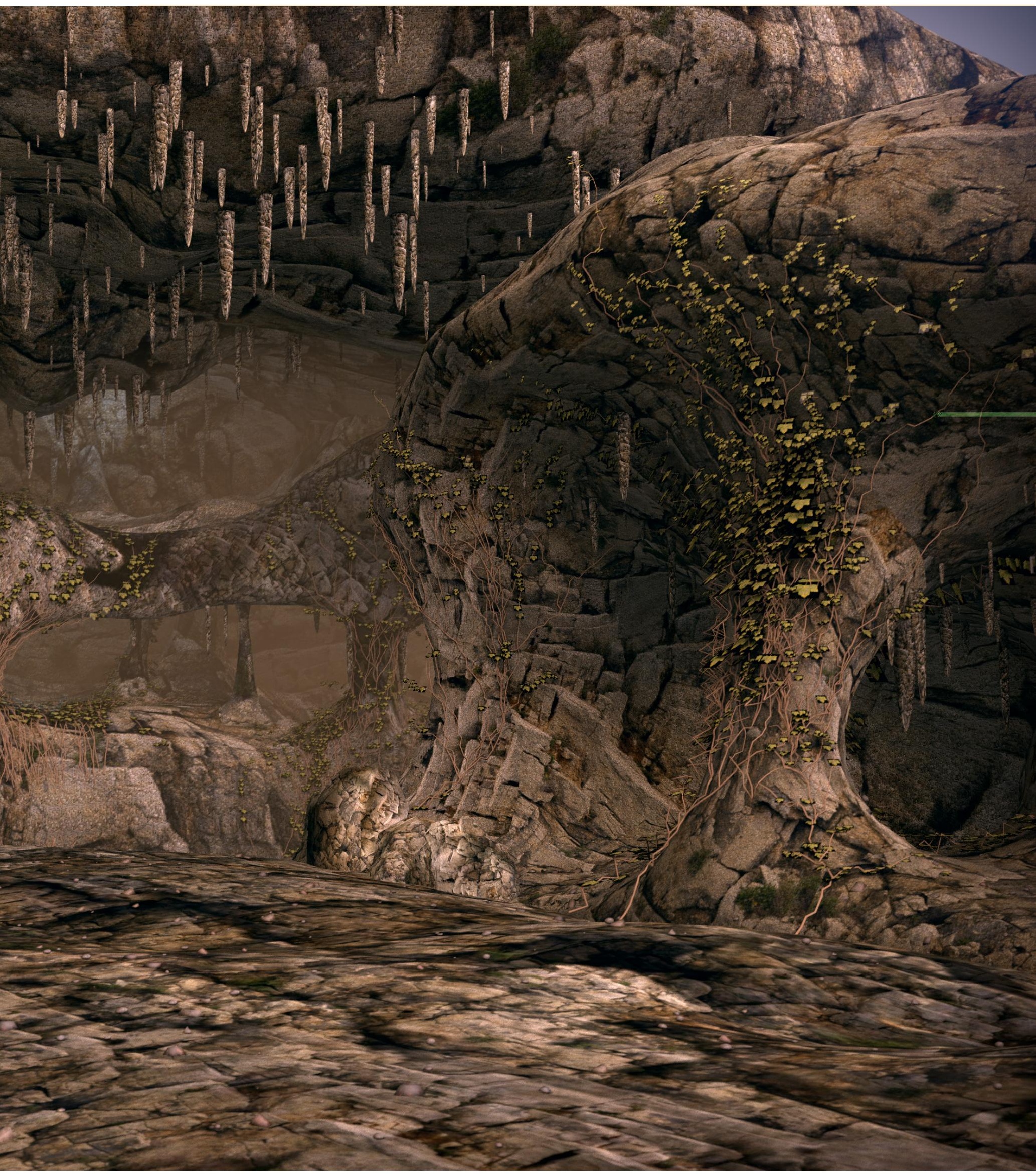




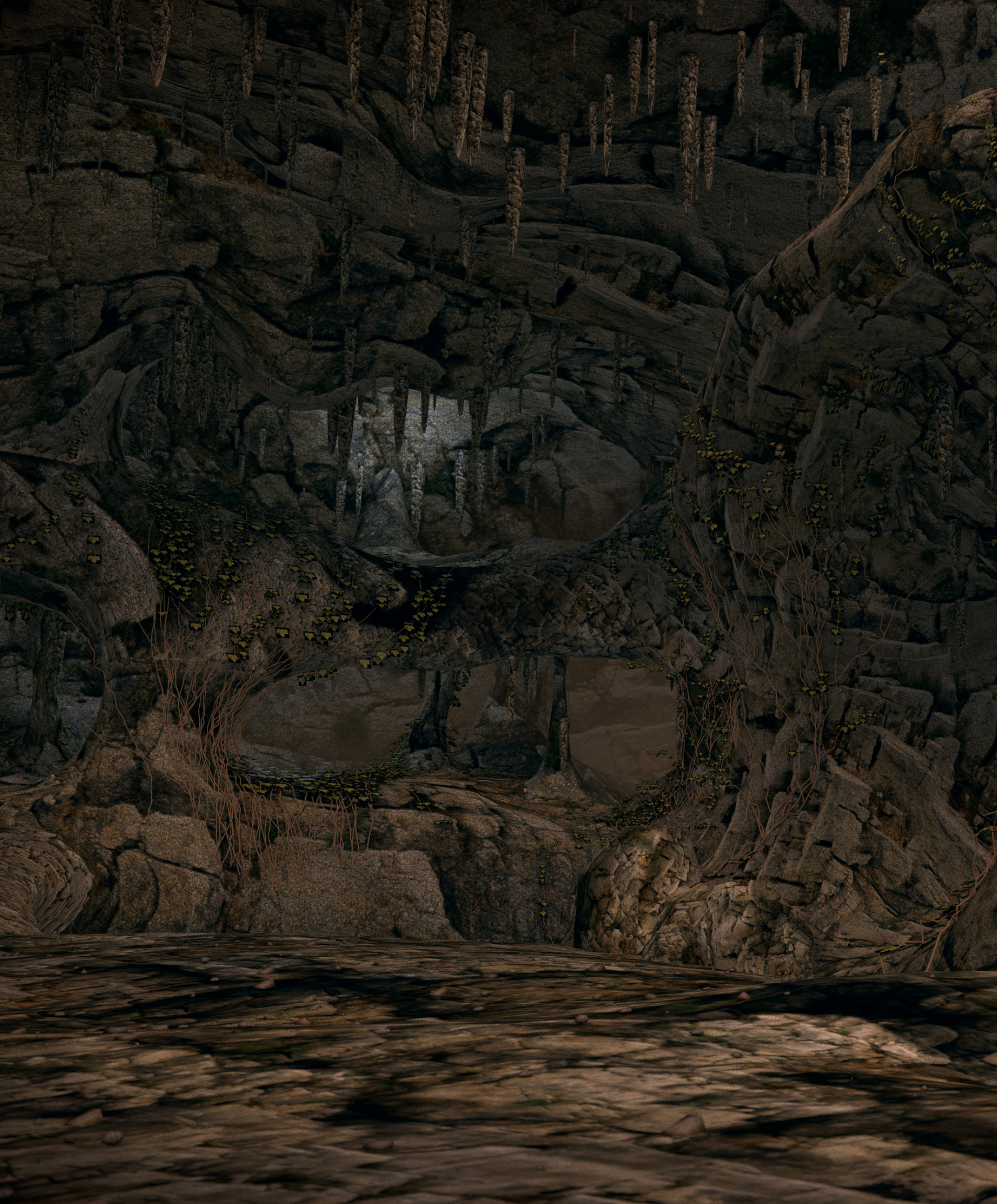




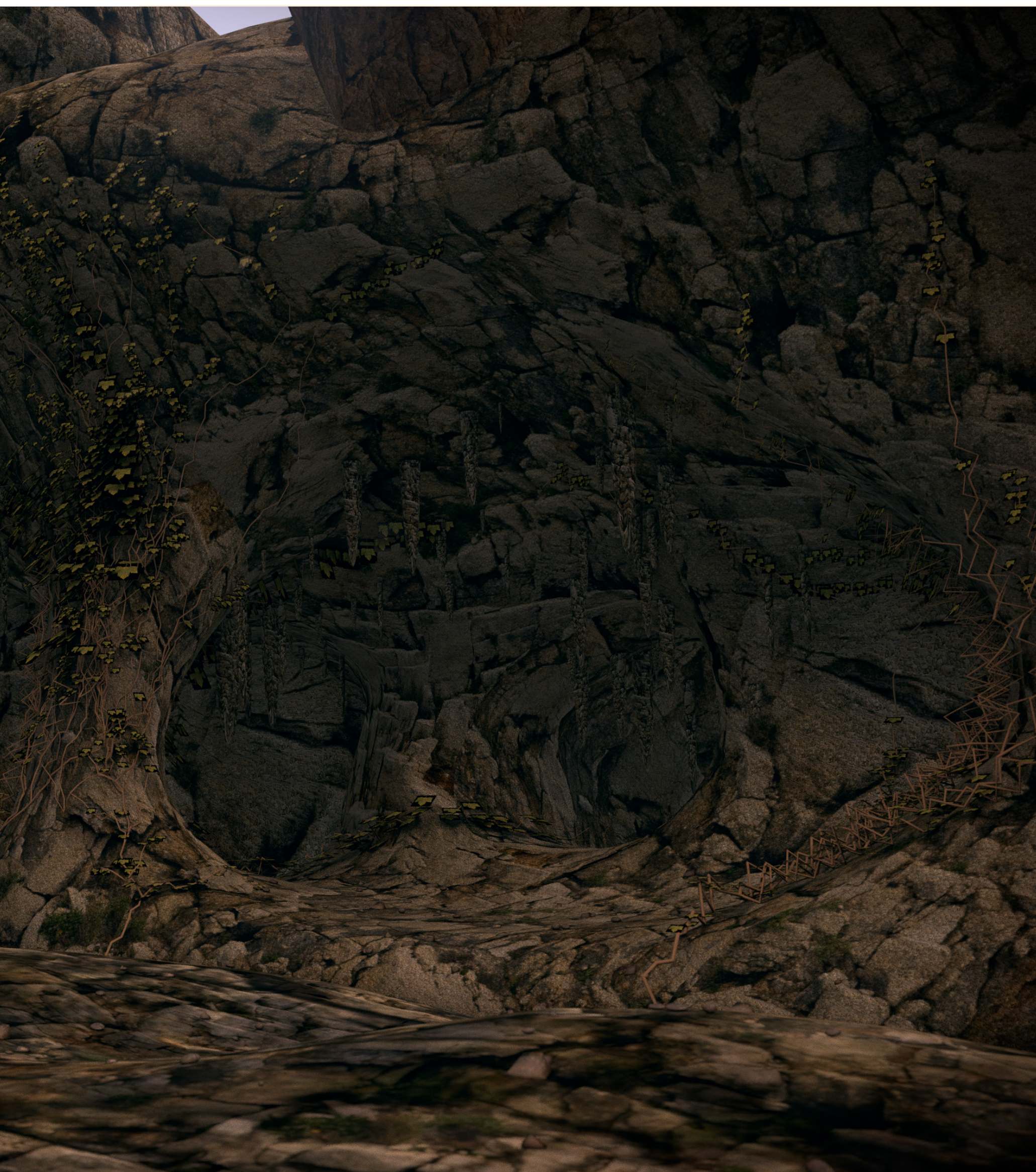




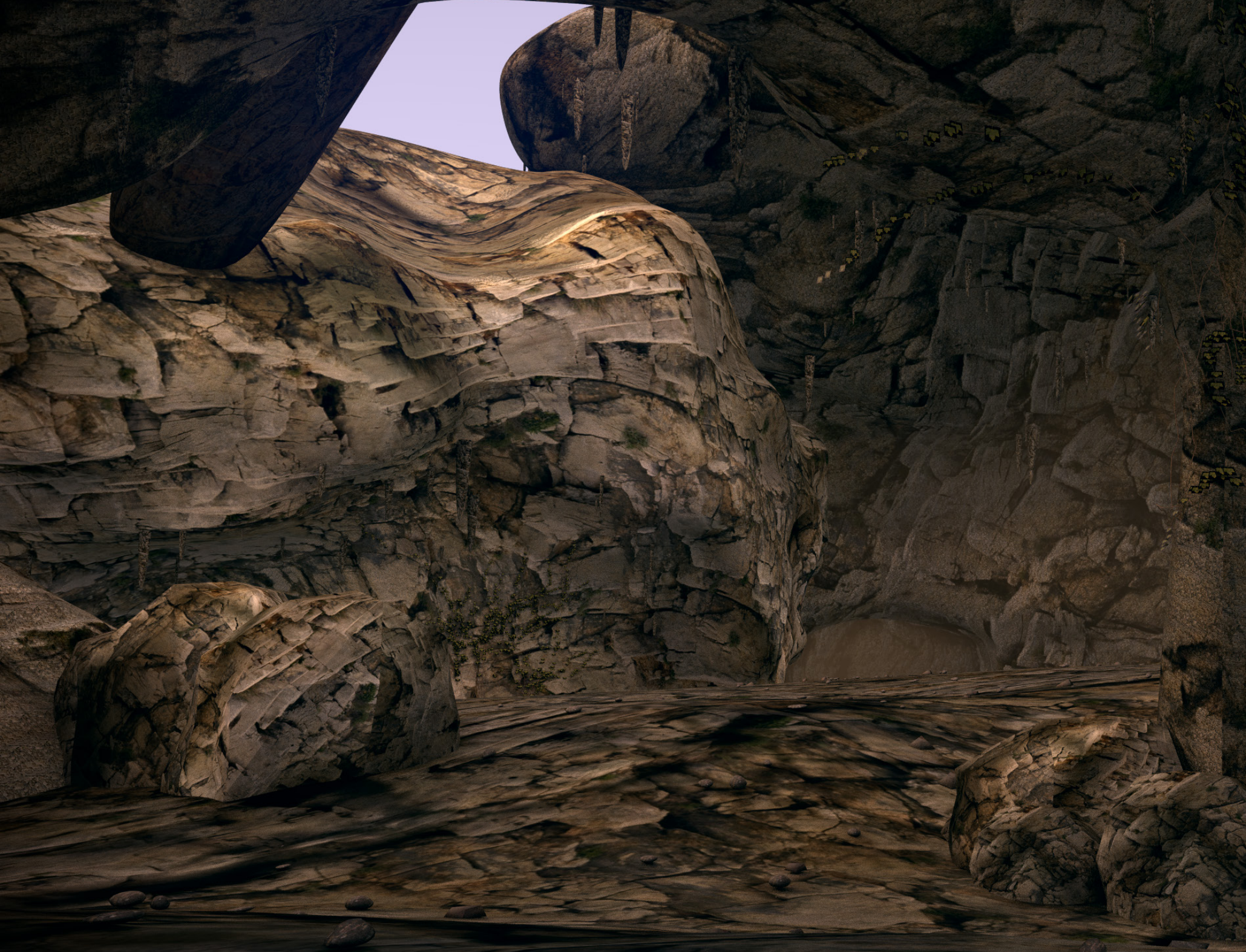


Chapter 5 - Conclusions 


\section{Conclusions}

\section{Summary}

This thesis started its investigation into bridging physical and virtual spaces by analysing theoretical discussions presented by New Media researchers. These discussions held the common stance that urban spaces were now augmented with technologies offered by mobile devices and wireless networks. The presence of these technologies had enabled for multiple spaces and situations to exist at the same time and at the same place in urban areas. However, despite the capabilities and spaces offered by these technologies, people still used these spaces separately, focusing on one space at a time. What it results in is a discord between the physical and virtual space as they are operated on different situation domains. Researchers in response to this have suggested that both the physical and virtual need to be considered more in urban planning and mobile media development.

Meanwhile, as the call for greater considerations between differing spaces were presented in New Media research, the Ubicomp and AR research fields continuously advanced alongside developments made in mobile technology. The developments in these areas enabled greater possibilities to be explored, some of which suggest, directly or implicitly, approaches that addressed the identified disparity issue between differing spaces. However, despite these advances offering novel approaches and innovations, the results of an analysis made with current precedent applications against the approaches by the researchers revealed that there was only a rudimentary usage of the techniques suggested.

This thesis therefore explored through mobile media design, the current capabilities of mobile devices to contribute to lessening the discord between physical and virtual space in urban areas. The explorations also examined approaches that further advanced Ubicomp and AR application developments in providing compelling and context aware mobile media. These investigations were envisioned from a design 
criteria created from a comparison of precedent works and research. The criteria offered a set of guidelines for creative approaches in bridging the physical and virtual.

The first design concept that was developed and explored was education focused, and was a scenario that sought to in illustrate extinct New Zealand Birds living in a virtual environment. This initial design presented its developments in incorporating sensor tracking movements for the AR user interface control, live data integration for dynamic weather variances, and virtual content designed to a physical location's boundaries and limits. These features were designed to established a greater contextual link between the application's virtual content and the physical surroundings of the user, thus lessening the disparity in the usage of the spaces. The resulting developments of this application were evaluated where some findings indicated that revised considerations were needed. These revised considerations were contributed towards a second design.

The revised elements from the first design were incorporated into the second design exploration called 'Echoes' which focused more on the design of the virtual environment. The shift of focus was to emphasize the virtual environment as a key element in establishing the link between the physical and virtual, as it provided the contextual background for the other virtual elements to not seem out of place when users viewed the application.

The design of Echoes was developed with the similar considerations to the first concept where the environment was designed to the boundary limits of Civic Square. The environment also incorporated the live data for dynamic environmental conditions, and the AR user interface control that engaged users to physically move and look around to explore the virtual mediascape. 


\section{Discussion}

This thesis investigated the physical and virtual divide in urban areas through exploring approaches developed for mobile media. The approaches centered on bridging the two spaces together to provide a greater connection between them which contributes to lessening the identified disparity in the usage of physical and virtual space in urban areas. By combining physical variances and limits into the design of the virtual content, a link is established between the spaces which provides greater contextual relevance and dynamic content for users to experience across both the physical and virtual in urban areas.

The design approaches in this thesis that contribute towards the main aim of bridging the physical and virtual divide and providing for an enhanced experience differed slightly from implementations found in the contextual analysis and precedent works. The design approaches were: utilising the boundaries of a physical location to define location tracked content, utilising a complete immersive 3D environment with AR controls, and integrating live data to reflect physical world conditions into a virtual mediascape.

The approach in utilising the spatial boundaries of the physical location to define location based virtual content adds a location driven context to the virtual elements. The current practices in AR development often places virtual signs, objects or animated media into a virtual overlay on top of the physical world to provide extra information to a tracked feature. This practice however, overlooks the other features in the environment that may interfere or obstruct the virtual content, causing a visual discord between the AR element and the physical setting. By linking a defined location and its surrounding limits of building facades and features to the virtual content, user's can visually identify the tracking of the virtual elements to their physical surroundings, offering an experience of viewing an alternate parallel world. 
This parallel virtual space was also displayed in a complete 3D virtual environment with AR camera controls to break away from the traditional overlay implementations. This approach differed to current research and precedent work implementations in that it presented not just a few virtual elements tracked to features in the physical world, but rather an full 3D virtual world. This approach engaged users into the virtual space where movements in the physical world would translate to exploring the virtual space as well. The mediaspace of the application is therefore evolved as an accessible world where the mobile device acts as the viewfinder.

The final design element that contributed towards bridging physical and virtual was the use of live data to drive atmosphere dynamics in the virtual environment. This approach was inspired from the reviewed Ubicomp context aware research where systems were developed to react to different situations to provide a more enhanced user experience. The approach explored here reflects the conditions of the physical setting into the virtual space, which reinforces the idea of a connection between the physical and virtual as the conditions of both spaces are operated on a single domain.

While the main aim of this thesis was to identify approaches towards bridging physical and virtual spaces in mobile media, it also aimed to encourage Ubicomp and AR application design to a higher level. Many of the approaches discussed in research are still rudimentary in practice considering the capabilities offered by mobile hardware. This is particularly true for the graphical implementations of $2 \mathrm{~d}$ digital maps and $3 \mathrm{~d}$ virtual overlays commonly found in location based, and AR media experiences. The approaches developed in this thesis evolves the rudimentary implementations to consider more enhanced forms, presenting immersive 3D environments instead of overlays, and dynamically driven content based on live data. 


\section{Implications}

The presented approaches in this thesis were illustrated in two scenarios. The first was an educational focused application that sought to deliver a user's experience that brought historical NZ animals back to life in an animated mediascape. The second was a focused development on the virtual environments that could be designed for location driven settings. Both these scenarios explored approaches that can be applied to a wide range of industries, in particular the Entertainment, Tourism, Film, and Gaming industries.

For the tourism industry, guided tours and audio walks to popular landmarks could be enhanced with virtual mediascapes that provide additional virtual areas for users to explore. These mediascapes could be animated environments that illustrate old sites or events that took place. Similarly for the entertainment, gaming and film industries, citywide narratives could take place on a massive user scale with real time location driven events. Influences from people at these events could change the narrative to affect the outcome of an overall story.

The developments could also be applied to Engineering industries in providing overlayed visualisations on top of the physical world. As the developments explored here have detailed immersive environments designed to physical world limits, urban planning and architecture could benefit from the display of AR virtual buildings that could be physically explored in urban space. This sort of application is a throwback to the original intent of AR which was conceived as a productivity aid for engineers. 


\section{Future Directions}

The approaches in this thesis towards bridging physical and virtual space have been explored primarily in regards to mobile media entertainment. While the developments explored are not exhaustive in their experimentation, they are offered as approaches for developers to consider. These approaches can be developed further in many ways for different industries, not just the entertainment industries.

In regards to research approaches in the Ubicomp and AR fields, one particular avenue for further research that deserves highlighting is the opposite focus of what is explored in this thesis: the design of the physical space. Augmented Space researchers have identified that both physical and virtual need to be considered in a unified domain for the disparity between them to be lessened or possibly resolved. The research in this thesis studied the virtual adaptation of physical elements and how it could be designed to enhance the contextual meanings and user experiences in physical urban space, thereby bridging the physical and virtual. However, the design of the physical space was not readily explored as an area that could also be designed and tailored for the virtual content. Exploring this direction would be of great benefit to the field and would offer greater opportunities for different media applications to be developed.

The research and developments that have been presented in this thesis can be applied to many applications, and it is hoped that by illustrating them here, future directions coupled with the advancing technologies and embedded communication networks in urban spaces, bring forth new innovations in Ubiquitous Computing, Augmented Reality and mobile media design. 


\section{Bibliography}




\section{Bibliography}

Abowd, D., Dey, A. K., Orr, R., \& Brotherton, J. (1998). Context-awareness in wearable and ubiquitous computing. Virtual Reality, 3(3), 200-211. doi:10.1007/ BF01408562

Abowd, G. D., Mynatt, E. D., \& Rodden, T. (2002). The human experience of ubiquitous computing. IEEE Pervasive Computing, 1(1), 48-57. doi:10.1109/ MPRV.2002.993144

Allen, P. (2008). Framing, Locality and the Body in Augmented Public Space. In A. Aurigi \& F. De Cindio (Eds.), Augmented Urban Spaces - Articulating the Physical and Electronic City (pp. 9-26). Burlington, VT: Ashgate.

Aurigi, A. (2008). Augmented Spaces. In A. Aurigi \& F. De Cindio (Eds.), Augmented Urban Spaces - Articulating the Physical and Electronic City (pp. 5-8). Burlington, VT: Ashgate.

Aurigi, A., \& De Cindio, F. (Eds.) (2008). Augmented urban spaces: Articulating the physical and electronic city. Burlington, VT: Ashgate.

Aydın, B., Gensel, J., Calabretto, S., \& Tellez, B. (2012). ARCAMA-3D - A context-aware augmented reality mobile platform for environmental discovery. (pp. 17-26). Berlin, Heidelberg: Springer Berlin Heidelberg. doi:10.1007/978-3-64229247-7_2

Azuma, R. T. (1997). A Survey of Augmented Reality. Presence - Teleoperators and Virtual Environments, 6(4), 355-385. 
Apple iPhone 5c specs. (2013). Retrieved from http://www.phonearena.com/ phones/Apple-iPhone-5c_id7983

Azuma, R., Baillot, Y., Behringer, R., Feiner, S., Julier, S., \& MacIntyre, B. (2001). Recent advances in augmented reality. Computer Graphics and Applications, IEEE, $21(6), 34-47$

Bell, G., \& Dourish, P. (2007). Yesterday's tomorrows: Notes on ubiquitous computing's dominant vision. Personal and Ubiquitous Computing, 11(2), 133-143. doi:10.1007/s00779-006-0071-x

Bolter, J., Engberg, M., \& MacIntyre, B. (2013). Media studies, mobile augmented reality, and interaction design. New York: ACM. doi:10.1145/2405716.2405726

Caudell, T. P., \& Mizell, D. W. (1992). Augmented reality: an application of heads-up display technology to manual manufacturing processes. System Sciences, 1992. Proceedings of the Twenty-Fifth Hawaii International Conference on (Vol. ii, pp. 659-669 vol.2).

Cheok, A. D., Yang, X., Ying, Z. Z., Billinghurst, M., \& Kato, H. (2002). Touch-space: Mixed realitygamespacebased on ubiquitous, tangible, and social computing. Personal and Ubiquitous Computing, 6(5), 430-442. doi:10.1007/s007790200047

Clark, A., Dünser, A., \& Grasset, R. (2011). An interactive augmented reality coloring book. SIGGRAPH Asia 2011 Emerging Technologies On - SA '11. doi:10.1145/2073370.2073394 
Clark, A., \& Piumsomboon, T. (2011). A realistic augmented reality racing game using a depth-sensing camera. Proceedings of the 10th International Conference on Virtual Reality Continuum and Its Applications in Industry, VRCAI '11 (pp. 499-502). New York, NY, USA

Crang, M., \& Graham, S. (2007). SENTIENT CITIES Ambient intelligence and the politics of urban space. Information, Communication \& Society, 10(6), 789-817. doi:10.1080/13691180701750991

Dow, S., Mehta, M., Lausier, A., MacIntyre, B., \& Mateas, M. (2006). Initial Lessons from AR Facade, an interactive augmented reality drama. Proceedings of the 2006 ACM SIGCHI international conference on Advances in computer entertainment technology, ACE '06. New York, NY, USA

Frith, J. (2012). Splintered Space: Hybrid Spaces and Differential Mobility. Mobilities, 7(1), 131-149. doi:10.1080/17450101.2012.631815

Gervautz, M., \& Schmalstieg, D. (2012). Anywhere interfaces using handheld augmented reality. Computer, 45(7), 26-31. doi:10.1109/MC.2012.72

Hornecker, E., Halloran, J., Fitzpatrick, G., Weal, M., Millard, D., Michaelides, D., Cruickshank, D. \& De Roure, D. (2006). “UbiComp in Opportunity Spaces: Challenges for Participatory Design", paper presented at ACM. pp. 47--56.

HTC One specs. (2013). Retrieved from http://www.phonearena.com/phones/HTCOne_id7678 
Iaconesi, S., \& Persico, O. (2012). ConnectiCity, augmented perception of the city. Corr, abs/1207.4291.

Iaconesi, S., Simeone, L., \& Hendrickson, C. (2011). An augmented reality third landscape. 254-257. doi:10.1145/2181037.2181080

Kerr, S., Rice, M., Teo, Y., Wan, M., Cheong, Y., \& Ng, J. et al. (2011). Wearable mobile augmented reality. Proceedings Of The 10Th International Conference On Virtual Reality Continuum And Its Applications In Industry - VRCAI '11. doi:10.1145/2087756.2087786

Kroeker, K. (2010). Mainstreaming augmented reality. Commun. ACM, 53(7), 19. doi:10.1145/1785414.1785422

Koleva, B., Schnädelbach, H., Benford, S., \& Greenhalgh, C. (2000). Developing Mixed Reality Boundaries. Proceedings of DARE 2000 on Designing augmented reality environments, DARE '00 (pp. 155-156). New York, NY, USA

Layar. (2014). Layar (Version 8.3.2) [Mobile application software]. Retrieved from https://play.google.com/store

Løvlie, A. (2009). Poetic augmented reality. Proceedings Of The 13Th International Mindtrek Conference: Everyday Life In The Ubiquitous Era On - Mindtrek '09. doi:10.1145/1621841.1621847

Manovich, L. (2006). The poetics of augmented space. Visual Communication, 5(2), 219-240. doi:10.1177/1470357206065527 
Morrison, A., Mulloni, A., Lemmelä, S., Oulasvirta, A., Jacucci, G., Peltonen, P., . . . Regenbrecht, H. (2011). Collaborative use of mobile augmented reality with paper maps. Computers \& Graphics, 35(4), 789-799. doi:10.1016/j. cag.2011.04.009

Niantic Labs@Google. (2014). Ingress (Version 1.61.2) [Mobile application software]. Retrieved from https://play.google.com/store

Nokia Lumia 1020 specs. (2013). Retrieved from http://www.phonearena.com/ phones/Nokia-Lumia-1020_id7876

PerBlue. (2013). Parallel Kingdom MMO (Version 5.0.12) [Mobile application software]. Retrieved from https://play.google.com/store

Petechuk, D. (2008). Virtual Reality. In K. L. Lerner \& B. W. Lerner (Eds.), The Gale Encyclopedia of Science (4th ed., Vol. 6, pp. 4582-4586). Detroit: Gale.

Puteko Ltd. (2014). colAR Mix (Version 2.6) [Mobile application software]. Retrieved from https://play.google.com/store

Quest-Com Co.Ltd.(2012). Droid Shooting (Version 2.02) [Mobileapplication software]. Retrieved from https://play.google.com/store

shadowcities. (2011,August, 26). Shadow Cities Trailer: It's a Game-It's Real [Video file]. Retrieved from https://www.youtube.com/watch?v=oMBvInCvEjM 
Samsung Galaxy S4 specs. (2013). Retrieved from http://www.phonearena.com/ phones/Samsung-Galaxy-S4_id7597

Sony Xperia Z specs. (2013). Retrieved from http://www.phonearena.com/phones/ Sony-Xperia-Z_id7539

Thomas, B., Close, B., Donoghue, J., Squires, J., Bondi, P. D., \& Piekarski, W. (2002a). First Person Indoor/Outdoor Augmented Reality Application: ARQuake. Personal and Ubiquitous Computing, 6(1), 75-86.

Thomas, B., Close, B., Krul, N., \& Piekarski, W. (2002b). Usability and Playability Issues for ARQuake. Retrieved from http://www.tinmith.net/papers/

Weiser, M., \& Brown, J. S. (1997). The coming age of calm technology. In Beyond calculation (pp. 75-85). Springer New York.

Willis, K. S. (2008). Places, Situations, and Connections. In A. Aurigi \& F. De Cindio (Eds.), Augmented Urban Spaces - Articulating the Physical and Electronic City (pp. 9-26). Burlington, VT: Ashgate.

Wither, J., Tsai, Y., \& Azuma, R. (2011). Indirect augmented reality. Computers \& Graphics, 35(4), 810-822. doi:10.1016/j.cag.2011.04.010

Zaharakis, I., \& Komninos, A. (2012). Ubiquitous computing multidisciplinary endeavour. IEEE Latin America Transactions, 10(3), 1850-1852. doi:10.1109/ TLA.2012.6222593 


\section{Figures}

Figure 1. Ingress [Screen Captures]. (2014).

Niantic Labs@Google. (2014). Ingress (Version 1.61.2) [Mobile application software]. Retrieved from https://play.google.com/store

Figure 2. Layar [Screen Captures]. (2014).

Layar AR. (2013, August, 15). Bring print to life with Layar! [Video file]. Retrieved from https://www.youtube.com/watch?v=ZR4eSmmPCxg

Figure 3. Shadow Cities [Screen Captures]. (2014). shadowcities. (2011, August, 26). Shadow Cities Trailer: It's a Game - It's Real [Video file]. Retrieved from https://www.youtube.com/ watch?v=oMBvInCvEjM

Figure 4. colAR Mix [Screen Captures]. (2014).

Puteko colAR. (2014, September, 8). colAR Mix Trailer [Video file]. Retrieved from http://colarapp.com/

Puteko colAR. (2014, August, 7). colAR Mix Preview - Shark Page (Dover Sampler Pack) [Video file]. Retrieved from http://colarapp.com/

Figure 5. Droid Shooting [Screen Captures]. (2014).

Quest-Com Co. Ltd. (2012). Droid Shooting (Version 2.02) [Mobile application software]. Retrieved from https://play.google.com/store

Figure 6. Parallel Kingdom MMO [Screen Captures]. (2014).

PerBlue. (2013). Parallel Kingdom MMO (Version 5.0.12) [Mobile application software]. Retrieved from https://play.google.com/store 
Figure 14. Martinson, P. (2005). Eastern Moa. Emeus crassus. From the series: Extinct Birds of New Zealand. [Watercolour]. Retrieved from http://collections. tepapa.govt.nz/Object/710922 under Creative Commons CC BY-NC-ND 3.0 NZ - http://creativecommons.org/licenses/by-nc-nd/3.0/nz/legalcode

Figure 15. Martinson, P. (2005). Haast's Eagle. Harpagornis moorei. From the series: Extinct Birds of New Zealand. [Watercolour]. Retrieved from http://collections. tepapa.govt.nz/object/710939 under Creative Commons CC BY-NC-ND 3.0 NZ - http://creativecommons.org/licenses/by-nc-nd/3.0/nz/legalcode

Figure 23. Google Maps. (2013). [Civic Square, Wellington, NZ] [Street map]. Retrieved from https://www.google.co.nz/maps/@-41.2889248,174.7774301,577m/ data $=! 3 \mathrm{~m} 1 ! 1 \mathrm{e} 3$ 

